\title{
THE EUROPEAN UNION AND THE MEMBER STATES: WHICH LEVEL OF GOVERNMENT SHOULD DO WHAT? AN EMPIRICAL ANALYSIS OF EUROPEANS’ PREFERENCES
}

\author{
FLORIANA CERNIGLIA \\ LAURA PAGANI
}

CESIFO WORKING PAPER NO. 2067

CATEGORY 1: PUBLIC FinANCE

August 2007

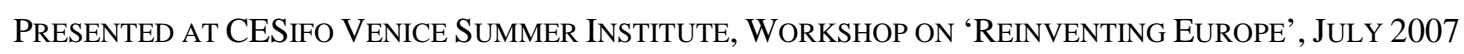

SupPort By the WGL Leibniz Association Within the ProjeCt “How to CONSTRuCt Europe”
An electronic version of the paper may be downloaded
- from the SSRN website:
- from the RePEc website:
wWw.SSRN.com
from the CESifo website:
Www.RePEc.org
www.CESifo-group.org/wp 


\title{
THE EUROPEAN UNION AND THE MEMBER STATES: WHICH LEVEL OF GOVERNMENT SHOULD DO WHAT? AN EMPIRICAL ANALYSIS OF EUROPEANS’ PREFERENCES
}

\begin{abstract}
In this paper we empirically study the preferences of European citizens concerning the allocation of powers between EU and the Member States using Eurobarometer data from 1995 to 2003. Descriptive analysis highlights a ranking of countries according to their level of Europeanism, and a quite clear pattern of preferences relative to the allocation of competences for specific policy domains. With econometric analysis, first we regress a measure of "Europeanism" on a number of individual characteristics and, second, we select some policy domains and investigate the determinants of preferences for centralisation of competences at the EU level. Also econometric analysis reveals interesting patterns regarding EU citizens' preferences for allocation of powers.
\end{abstract}

JEL Code: H11, H77.

Floriana Cerniglia

Department of Economics

University of Milan Bicocca

Piazza Ateneo Nuovo, 1

20126 Milan

Italy

floriana.cerniglia@unimib.it
Laura Pagani

Department of Economics

University of Milan Bicocca

Piazza Ateneo Nuovo, 1

20126 Milan

Italy

laura.pagani@unimib.it 


\section{Introduction}

A central issue with which the European Union (EU) had to cope with, since its foundation, is the heterogeneity of preferences among its member States regarding the policy areas and prerogatives in which the EU should intervene most or, stated differently, regarding the provision of public goods and common policies for the member States. The issue strongly pertains to the question of the allocation of powers between the EU and the member States. And in fact, the EU has always been faced with the difficult task of finding out a correct balance between the need to centralize, coordinate or harmonize some policies in order to fulfil its values and objectives (especially those stated in the various Treaties) without weakening the autonomy and sovereignty of member States.

The introduction of the principle of subsidiarity in the Maastricht Treaty in 1992 was intended to offer a principle of governance to cope with this dilemma. Recently, a further innovation has been put forward by the Constitutional Treaty by establishing a more clear allocation of competences between the European Union and the member States (exclusive, shared and supporting competences).

The question of heterogeneity of preferences across governments and the allocation of powers among levels of governments is related to the literature on fiscal federalism, which dates from Oates' seminal work (1972). Oates's decentralization theorem heavily relies on heterogeneity of preferences to show the optimal allocation of powers among different levels of government. If preferences on local public goods are different among local governments, it is possible to show that local provision of public goods improve allocative efficiency ${ }^{1}$. In other words local governments "are closer to the people" and better match the preferences of their citizens ${ }^{2}$. Since Oates' work, a huge amount of work has been done in the literature. For instance, there is a strand of literature which offers normative criteria on the optimal allocation of powers among levels of government by highlighting the trade-off between heterogeneity of preferences and scale economies in public good provision. Briefly, according to this literature ${ }^{3}$, the main advantages of centralization of certain policies are exploitation of economies of scale and internalization of spillovers, but these gains have to be balanced with the "cost of uniformity" in providing those good, since this uniform provision may conflict with diverse citizens' preferences ${ }^{4}$.

Turning our attention to the EU, what we have seen in the last decades is that European institutions perform and deliver policies in contrast to the normative prescription of the theory. Put differently, EU is quite often deeply involved in policy areas where heterogeneity of preferences among

\footnotetext{
${ }^{1}$ It is also well known that the theorem presumes that the alternative to local provision is a centrally determined, uniform level of public good.

${ }^{2}$ In the literature this argument is known as the preference-matching argument.

${ }^{3}$ For a survey see Alesina and Spolaore (2003)

${ }^{4}$ This literature also shows under which circumstances this conflict on public good provision may lead to the break-up of a political union.
} 
European citizens and member States are high. On the other hand, EU is not deeply involved in policy areas where the existence of huge economies of scale and externalities should dictate for a provision at the European level instead of a provision by member States.

Moreover, in the last decades we have also seen that whenever more integration and coordination of policies has been achieved (or when the will of more uniformity in some policy areas has been put forward or announced) European citizens have been less enthusiastic that their leaders about all this ${ }^{5}$. The recent snub to the Constitutional Treaty by Dutch and French citizens has been a huge shock in this respect, especially because it was the first time a founder member had done so. Let us quote what The Economist wrote very recently in a special Report on the European Union's $50^{\text {th }}$ birthday: "The biggest failing of the EU has long been the yawning gulf between the union, as both a project of integration and a set of institutions, and the mass of its citizens. Nobody could pretend that, when French and Dutch voters voted against the constitution in 2005, they were objecting merely to specific provision in the text; nor that they were just using the opportunity to give their governments a good kicking. It seems much more likely that they were expressing a general feeling of resentment towards the European project and its remoteness. This feeling is more emphatic in some countries than in others, but it seems to be strong everywhere"

So, is this feeling of resentment toward the "European project" correct? What are Europeans views about what EU should do? Is it time to repatriate more power back to Member States?

In this paper we intend to shed some lights on this issue and, in particular, our main goal is to evaluate empirically the preferences of European citizens regarding the assignment of competencies between EU and member States, both overall and in a certain number of policy areas.

To the best of our knowledge, other empirical works studying the role of preferences of European citizens in the assignment of competencies between the EU and the national states are Ahrens and Meurers (2004) and Alesina, Angeloni and Schuknecht (2005). They use our same dataset (Eurobarometer survey) but our study is different as we do not restrict to descriptive analysis (as these works do) but we perform econometric analysis using a huge set of explanatory variables to explain heterogeneity of preferences across European citizens and countries.

The outline of the paper is as follows. Section 2 recalls the main arguments used in the theory of fiscal federalism in describing the optimal assignment of responsibilities and functions to different levels of government; Section 3 describes the data set we used in our empirical work; Section 4 offers a descriptive analysis of preferences of European citizens; Section 5 presents results from econometric analysis; Section 6 concludes and summarizes our findings.

\footnotetext{
${ }^{5}$ Examples are not only the French and Dutch no the Constitutional Treaty, but also the Irish no to the Nice Treaty, the Danes rejection of the Maastricht Treaty.
} 


\section{Approaches to the assignment of policies to different levels of government: from theory to practice in the European Union}

The European Union is the result of a bottom-up process of federalization among sovereign States. During this process, started 50 years ago, States gave up some of their powers and delegate them to the European Institutions. Devolution of powers to the European Union or unanimous agreements by States in favour of common policies have been very "painful" in many occasions, since countries belonging to the EU are heterogeneous in many respects.

It follows that one of the most serious problem with which the EU had to cope with, since its foundation, concerns the optimal attribution of policy responsibilities between the European institutions and the member States. It is not surprising that the question has been one of the most debated issues inside Convention's works, whose mandate was to propose a Draft Constitution.

So, to date, the EU is no longer a single economic agreement among sovereign States, but it presents many characteristics of an economic union or a federation: there is an internal market, a common currency and many other common policies ${ }^{7}$. At the same time, in analysing EU institutions, drawing a strong parallelism with the working of other existing federations may be of limited use for many reasons. First of all the European institutions (the Commission, the European Council, the Council of the European Union, the Parliament and the Court of Justice) perform a different role compared to the working of similar institutions of other federal countries, given that such institutional set-up is not the result of the fundamental division of legislative, executive and regulatory powers, but it is a very original outcome of an ongoing dialogue - based on the intergovernmental and communitarian method - among the above mentioned institutions. Then the question is: what is the European Union if it is neither an economic agreement nor a federal state? Well, very simple, the European Union is a union of States which in order to take advantage of economies of scale and internalize externalities should provide public goods and policies were benefits of scale are large and heterogeneity of preferences among member States and European citizens is low ${ }^{8}$.

Exploitation of economies of scale, internalization of externalities, heterogeneity of preferences in public goods provision are issues strongly related to the vast literature on fiscal federalism which, spurred by Oates (1972), provides clear guidelines for the optimal allocation of functions among levels of governments. Briefly, the normative principles are that policies where economies of scale

\footnotetext{
${ }^{6}$ The Economist, A special Report on the European Union, March 17th-23rd 2007, p. 16.

${ }^{7}$ For more discussion on the institutional aspects of EU organization see Berger and Moutos (2007), Bordignon (2007), Alesina and Perotti (2004) and Tabellini (2003).

${ }^{8}$ According to Alesina and Spolaore (2003, chapter 12, p. 205) "To some extent Europe is a union of states that serves the purpose of taking advantage of economies of scale, and creating a level of government with limited prerogatives were benefits of scale are large and heterogeneity of preference low. The principle of subsidiarity that should be the basis of European integration is consistent with this interpretation".
} 
and/or externalities have a predominant role should be allocated at the highest level of government. In contrast, whenever heterogeneity of preferences is strong, policies should be allocated at the lowest level.

Oates's results heavily depend on the assumptions of a benevolent government and policy uniformity. New approaches (in particular the political economy approach) relax these assumptions by modelling in a more realistic way the political process, but results are still the same ${ }^{9}$. In other words the "preference-matching argument" is still valid: local public goods provision improves allocative efficiency as better matches to the preference of citizens of those local jurisdictions.

There are other recent approaches (drawing on several lines of literature: principal-agent problems, the economics of information, the new theory of firm, the theory of contracts) which suggest new perspectives on centralization and decentralization ${ }^{10}$.

In brief, the pros and the cons of decentralization proposed by this strand of research may be listed in the Table (or decision matrix) which follows:

Table 1. The (de)centralization matrix

\begin{tabular}{|c|c|c|}
\hline Criteria & Decentralization & Centralization \\
\hline $\begin{array}{l}\text { Individual preferences for local } \\
\text { public goods and services }\end{array}$ & Heterogeneous & Homogeneous \\
\hline Economies of scale & No & Yes \\
\hline $\begin{array}{l}\text { Spillovers or } \quad \text { geographical } \\
\text { externalities }\end{array}$ & No & Yes \\
\hline Congestion costs & Yes & No \\
\hline Information and decision costs & $\begin{array}{l}\text { Increase with the number of } \\
\text { participants }\end{array}$ & $\begin{array}{l}\text { Remain low when the number of } \\
\text { participants increases }\end{array}$ \\
\hline Fiscal Competition seen as positive & Yes & No \\
\hline Fiscal Competition seen as harmful & No & Yes \\
\hline
\end{tabular}

Turning our attention to the working of the EU institutions, what does the decision matrix suggest that the EU and member States should do? In very general terms and looking at the first three lines of the matrix the answer is simple: functions with more externalities and economies of scale and less heterogeneity of preferences among countries should be centralized at the European level.

\footnotetext{
${ }^{9}$ For a survey see Lockwood (2006).

${ }^{10}$ For results proposed by this literature see Ahmad and Brosio (2006).
} 
Next, as the EU is increasing in size, both congestion costs and information costs call for decentralization $^{11}$ and as for fiscal competition in EU, results in the literature are mixed ${ }^{12}$.

Therefore, in practice, the optimal balance of power between the EU and member states is far from being clearly defined. The critical question is how to evaluate all the European responsibilities, policies and functions along the trade-off between the benefits of more coordination or common policies and the costs of homogeneity, bearing in mind that in EU the issue of heterogeneity among national preferences is probably the most relevant phenomenon to consider in designing the optimal allocation of policies ${ }^{13}$. Moreover, it is beyond doubt that recent enlargements have brought in EU a significant increase in heterogeneity along many dimensions (economic structure, political institutions, social and cultural differences, social needs) ${ }^{14}$.

\subsection{The assignment of competencies between the $\mathrm{EU}$ and the national states in practise}

At this stage, let us also look at the working of the EU in practice to understand to what extent EU's policy prerogatives satisfy the criteria listed in Table 1 . It is not an easy task.

Looking at the EU Treaties signed by member states so far, EU involvement spam to a huge array of policy areas ${ }^{15}$. So, it is not easy to detect how deep the involvement by EU institutions in each of these policy areas is. To this aim a useful reference is the work by Alesina and Spolaore (2003, chapter 12) and Alesina, Angeloni and Schuknecht (2005), who built a set of indicators to measure the "policy making intensity" of the European Union ${ }^{16}$.

A quick look at Table 2 shows that EU institutions are involved in many policy responsibilities, but extensive involvement is only in monetary policy, internal market, agriculture, fisheries, and common trade policy.

European institutions are not present in areas were economies of scale and externalities call for a deep European intervention (for instance may be the case of research, environment, defence and foreign policy). So, Table 2 shows unambiguously that not all the arguments proposed by the fiscal federalism theory (as summarized in Table 1) apply in practice.

If we stick to realities, when decisions to adopt common policies have to be taken through a political bargaining process among member States, it is very difficult to enforce the argument of

\footnotetext{
${ }^{11}$ Local governments have more information about citizens' preferences. In the literature it is also claimed that cultural differences between citizens are correlated with the size of countries, and therefore a larger population will be less homogeneous; for more discussion see Alesina and Spolaore (2003).

${ }^{12}$ See Wellisch (2000) and Wilson (2006)

${ }^{13}$ See below for more discussion.

${ }^{14}$ For evidence on increase in preference heterogeneity after EU enlargement see Ahrens et al. (2004).

${ }^{15}$ For more details and discussion for each of this policy area see http://europa.eu/pol/about_it.htm.

${ }^{16}$ To build this measure they look at the legislative production (the Treaties as well as the secondary legislation and the enforcement via the Court of Justice) of the EU. They find that the volume of EU legislation has increased especially in the period 1971 to 2000 . Higher EU involvement is in international trade and common market; small attention is devoted to international relations and defence.
} 
economies of scale and externalities. Instead, it can be reasonably supposed that in this bargaining process, in deciding on competence allocation to the EU, what prevail are the different views and interests among member States and citizens.

\section{Table 2. Policy responsibilities of the EU and their extent}

\begin{tabular}{|c|c|c|c|}
\hline & Extensive & Shared & Limited \\
\hline \multicolumn{4}{|l|}{ Economic and Social Areas } \\
\hline Competition & & $\mathrm{X}$ & \\
\hline Cultural Policy & & & $\mathrm{X}$ \\
\hline Regional Policy & & $\mathrm{X}$ & \\
\hline Employment and social policy & & $\mathrm{X}$ & \\
\hline Enterprise Policy & & $\mathrm{X}$ & \\
\hline Equal opportunities & & $\mathrm{X}$ & \\
\hline Industrial policy & & $\mathrm{X}$ & \\
\hline Public health & & & $\mathrm{X}$ \\
\hline Solidarity and welfare & & & $\mathrm{X}$ \\
\hline Consumer policy & & $\mathrm{X}$ & \\
\hline Monetary policy & $\mathrm{X}$ & & \\
\hline Education, training and youth & & & $\mathrm{X}$ \\
\hline Environment & & $\mathrm{X}$ & \\
\hline Internal market & $\mathrm{X}$ & & \\
\hline Research and technology & & $\mathrm{X}$ & \\
\hline Trans-European networks and mobility & & & $\mathrm{X}$ \\
\hline \multicolumn{4}{|l|}{ Sectoral policy } \\
\hline Agriculture & $\mathrm{X}$ & & \\
\hline Fisheries & $\mathrm{X}$ & & \\
\hline Transportation & & $\mathrm{X}$ & \\
\hline Information and telecommunications & & $\mathrm{X}$ & \\
\hline Audiovisual policy & & & $\mathrm{X}$ \\
\hline Energy & & $\mathrm{X}$ & \\
\hline \multicolumn{4}{|l|}{ External policies } \\
\hline Common foreign and security policy & & & $\mathrm{X}$ \\
\hline Development policy & & $\mathrm{X}$ & \\
\hline Humanitarian aid & & $\mathrm{X}$ & \\
\hline Common trade policy & $\mathrm{X}$ & & \\
\hline \multicolumn{4}{|l|}{ Justice and home affairs } \\
\hline Asylum, external borders, immigration & & $\mathrm{X}$ & \\
\hline Judicial and police cooperation & & $\mathrm{X}$ & \\
\hline Drugs & & $\mathrm{X}$ & \\
\hline Trade in human being & & & \\
\hline
\end{tabular}

Source: Reprinted from Alesina and Spolaore (2003), ch. 12 
To conclude, despite all the theoretical guidelines, it is possible to acknowledge that a system of decentralization (multilevel government) is not only a form of organization to be implemented for "economic efficiency". In practise, (de)centralization of powers is the outcome of a quite complex political and institutional process. This is the reason why we observe across the world a great variety of federal or decentralized arrangements ${ }^{17}$. So, European Union is another example of multilevel government. Distinct economic and societal characteristics influence and inform the politics of intergovernmental relations in each country and, obviously, these characteristics reflect citizens' preference or, to put it differently, voters' preferences. Therefore it is extremely interesting, especially in the European contest, to assess more carefully and empirically which economic, political and social factors may drive and reflect citizens' preferences toward the assignment of public responsibilities to different levels of governments.

For instance, the issue at stake may be to gain a more precise understanding of whether the allocation of competences between the member states and the European Union, as introduced by the Constitutional Treaty, accomplishes Europeans' preferences. To be more specific, we know that defence and foreign policy have not been reassigned exclusively to the European level, contrary to every prescriptions of the theory. Therefore, we need to understand what European citizens think about the allocation of these powers and, most important, we need to have a clearer picture about determinants influencing these preferences. This is the task of our work which we investigate in sections which follow.

\section{Data and variable description}

In this study we use data from various waves of Eurobarometer, which is a public opinion survey conducted on behalf of the EU Commission two or more time a year; each survey consists in approximately 1000 face-to-face interviews per UE Member State (except Germany: 2000, Luxembourg: 600, United Kingdom 1300) ${ }^{18}$. The universe of the surveys is citizens aged 15 and over residing in EU15. In each Eurobarometer issue an identical set of question is asked to Member States' citizens, thus these questions are repeated over time. In addition to Standard Eurobarometer, Special Eurobarometer issues are carried out quite often on specific issues ${ }^{19}$.

The period we consider spans the years 1997-2003. More specifically, we have selected the Eurobarometer surveys containing information regarding the desired allocation of competences by European citizens. These surveys are numbers 43.1 (which refers to 1995), 48 (1997), 49 and 50 (1998), 51 and 52 (1999), 53 and 54.1 (2000), 56.2 (2001), 57.1 and 58.1 (2002), 59.1 and 60

\footnotetext{
${ }^{17}$ See Dafflon (2006) for more discussion.

${ }^{18}$ Unfortunately, the respondents are not the same in the different surveys, so we could not perform panel analysis.
} 
(2003). We built a single data set joining the 13 surveys; the result is a pooled cross-section data set consisting of 209,469 observations.

In each of the selected surveys, for different policy areas EU citizens are asked whether they think that the corresponding policy decisions should be taken by own country government or jointly within the European Union. More precisely, the question in the survey is:

"Some people believe that certain areas of policy should be decided by the (NATIONAL) government, while other areas of policy should be decided jointly within the European Union. Which of the following areas of policy do you think should be decided by the (NATIONAL) government, and which should be decided jointly within the European Union?"

We believe that this question gives a fairly good overview of how European citizens perceive the European Union's intervention in supplying policies and public goods or, stated differently, what European citizens think about the allocation of powers between the EU and member States. In interpreting this question, the exact meaning of "jointly" may be unclear. In our view, a respondent choosing jointly shows a willingness to transfer such policy to the EU.

The policy areas over which the respondents are asked to express themselves changes from survey to survey ${ }^{20}$. We have focused on those areas present since the first survey (43.1) and on those included subsequently (i.e., we have not considered areas present in one survey and removed afterward). There are 16 areas present in all the 13 considered surveys, 18 areas present since survey 50, 25 since survey 52, 26 since survey 56.2 and 27 since survey $57.1^{21}$.

The data set contains also demographic and other background information. Some of these are present in all the 13 surveys, so we could perform econometric analysis on the whole joined sample. The corresponding variables are country of residence, gender, age, family role (head of the household or not), household income, marital status, education, occupation, political side, attitude towards own country EU membership and judgement of the overall benefits own country has received from being a member of the European Union. Other information are present only in different subsets of the 13 surveys, so in order to exploit also these information we replicated econometric analysis on different sub samples depending on the variables we wanted to consider. These variables are: level of knowledge of the EU, its policies and its institutions, whether the respondent sees himself/herself European in the future, life satisfaction, satisfaction with the way democracy works in his/her country and in the EU, frequency of news learning by television, daily papers and radio, religion, area of living, whether the respondent is proud to be of his/her own

${ }^{19}$ For instance, after the signature of the Constitutional Treaty by the Head of State and Government, a special Eurobarometer issue (n.214) was commissioned by the European Commission and carried out in the 25 Member States focusing on the levels of real knowledge of the draft Constitution.

${ }^{20}$ Notice that in the work we will use policy area, policy issue, policy domains, policy responsibilities, competences and functions in an interchangeable way.

${ }^{21}$ See the Appendix for a detailed description of the policy areas. 
nationality and to be European, whether the respondent think that his/her country EU membership brought personal advantages to him/her and the probability to vote in own country and in EU elections.

\section{Descriptive analysis: a survey of preferences of European citizens on EU activities from} 1995 to 2003

In this section we present a first sketch of the preferences of European citizens regarding the allocation of competences or policy areas between EU and member States. In the subsequent analysis we follow Alesina et al. (2005), so that for each policy areas and country we compute the (integer of the) balance of the answers to the question relative to the preferred allocation of competences (PA) calculated in the following way: $\mathrm{PA}=[(\mathrm{EU}-\mathrm{N})(1-\mathrm{DK} / 100)]$, where EU represents the percentage of people stating that the corresponding area of policy should be decided jointly within the European Union, $\mathrm{N}$ the percentage of people stating that the corresponding area of policy should be decided by the national government, and DK the percentage of people who don't know to whom the competence should be assigned ${ }^{22}$. The larger the value of PA, the higher the (percent) number of people that have expressed a preference for a jointly (or shared) responsibility, weighted for the undecided. The values range from -100 to +100 ; a value of $+100(-100)$ means a unanimous preference for shared (national) competence.

Compared to our work, Alesina et al. (2005) give a very static picture on preferences of European citizens, as they consider only one Eurobarometer (Spring 2001 issue). In our work instead we provide a very broad picture given that, as said, we consider 8 years (from 1995 to 2003), a larger group of countries, and a larger set of policy areas.

To summarise some patterns which emerge, we report in this section only some graphs ${ }^{23}$. For each policy domain, Graph 1 reports on the x-axis the mean value of PA by country and survey and on the $y$-axis its standard deviation. Accordingly, if a certain policy domain lies in the first quadrant, the majority of EU citizens in the period under analysis think the relative decisions should be taken jointly within the EU, while a domain lying in the forth quadrant indicates that for the majority of EU citizens the decisions should be taken by national governments. Moreover, the higher the value on the $y$-axis, the greater is heterogeneity of preferences by country for the correspondent domain ${ }^{24}$.

\footnotetext{
${ }^{22}$ We follow Alesina et al. (2005) and multiply (EU-N) by (1-DK/100), so that "the balance receives a lower weight if the share of uncertain respondents is large".

${ }^{23}$ Tables with computation of PA for each survey and country are available from the Authors upon request.
} 


\section{Graph 1: Mean and standard deviation of preferences - Average 1995-2003 by country}

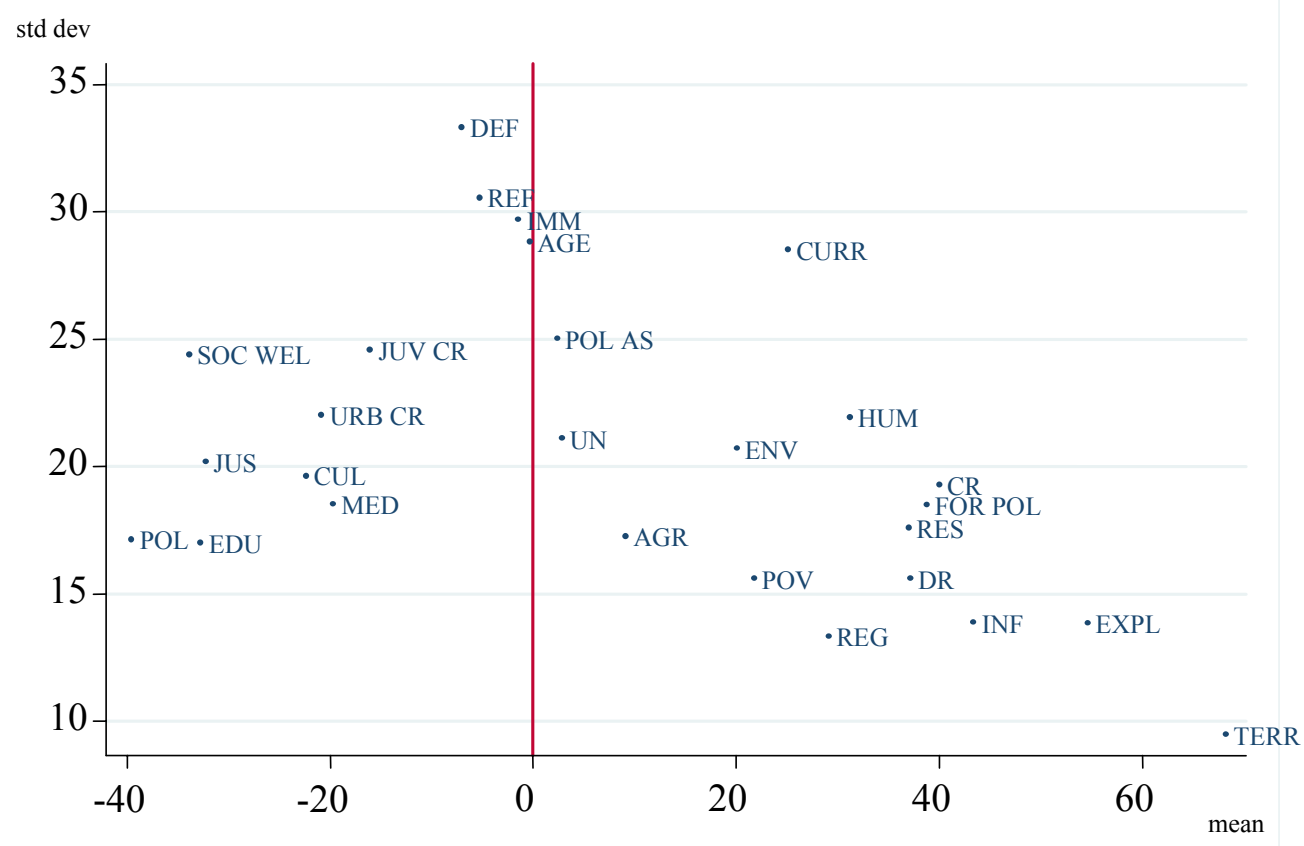

$\mathrm{DEF}=$ defence; $\mathrm{REF}=$ accepting refugees; $\mathrm{IMM}=$ immigration; $\mathrm{CURR}=$ currency; $\mathrm{AGE}=$ ageing; $\mathrm{POL} \mathrm{AS}=$ political asylum; $\mathrm{SOC}$ WEL $=$ health and social welfare; JUV $\mathrm{CR}=$ juvenile crime prevention; URB $\mathrm{CR}=$ urban crime prevention; HUM=humanitarian aid; UN=unemployment; $\mathrm{ENV}=$ environment; JUS=justice; $\mathrm{CUL}=$ culture; $\mathrm{CR}=$ crime; $\mathrm{MED}=$ media; $\mathrm{FOR} \quad \mathrm{POL}=$ foreign policy; $\mathrm{POL}=$ police; $\quad \mathrm{EDU}=$ education; AGR=agricolture; RES=research; POV=poverty; DR=drugs; REG=regional aid; INF=information EU; EXPL=fight against exploitation of human beings; TERR=terrorism.

The first interesting thing to be noticed is that policy areas for which the values of PA are both very high and very low are characterised also by low heterogeneity among countries (the standard deviation is low), while domains with close-to-zero value of PA are also characterised by a high value of the standard deviation. From the one side, this means that for some policy issues the majority of countries are strongly in favour either of a jointly allocation (which means pro-EU) or of an exclusively national competence. For example, this happens for terrorism (PA $=68$ and standard deviation $=9.5)$ or for education $(\mathrm{PA}=-33$ and standard deviation $=17)$. On the other side, the close-to-zero value of PA we observe for some policy issues stems from high heterogeneity of preferences among countries. The most important case is defence, which has a close-to-zero value of PA (around -7) while its standard deviation is quite high (33.3). Indeed, in the case of defence, citizens' attitudes ranges from strong favour for a national competence (Finland, $\mathrm{PA}=-78$ ) to preference for a joint assignment (The Netherlands, $\mathrm{PA}=+37$ ).

Turning to average preferences for domains allocation, we can divide policy areas in three groups: the first contains domains for which we observe a strong preference for national assignment (police, health and social welfare, education, justice, culture, juvenile and urban crime prevention and basic

\footnotetext{
${ }^{24}$ Since data reveal no substantial change by year, a high value of the standard deviation reflects mostly high preference
} 
rules for broadcasting and press). The second group refers to policy domains for which there is no strong preference neither for national competence nor for a joint competence (PA close to zero); these areas are defence, policies for accepting refugees, immigration, policies for tackling the challenges of an ageing population, rules for political asylum, unemployment and agriculture. For these areas in general we observe also a high value of the standard deviation. The third group contains areas for which, on average, we observe a preference for centralization, that is a preference for transferring the respective powers to Europe; these areas are environment, fight against poverty and social exclusion, currency, regional aid, fight against trade in and exploitation of human beings, research, fight against drugs, foreign policy, fight against organised crime, information about the EU, its policies and institutions, cooperation and humanitarian aid and fight against international terrorism.

So far, Graph 1 has shown a first broad picture of EU citizens' preferences averaging PA values by country and year. To detect more information on differences across countries for different policy areas, we now turn our attention to values by country and policy domain. Results are reported in Graph 2.

The first thing to be noticed is that there are countries which, independently of the policy area considered, are always either in favour of a shared competence, either of a national competence. In other words, there are countries strongly pro-European and countries more against Europe. The former group includes Italy (which ranks among the 5 more Europeanist countries for 25 areas over the 27 considered), Belgium, and Spain. The latter group includes Sweden (which ranks among the last five Europeanist countries for 25 areas over the 27 considered), Finland, UK and, to a lesser extent, Denmark. Turning the attention to the single policy areas, the picture which emerges is that for some areas all member States strongly agree to allocate the relative competence to the European level; this is the case for example of research, foreign policy, fight against drugs, regional policy, fight against poverty and social exclusion, information about the EU, its policies and institutions, environment (with exception of Finland and Sweden), currency (with exception of the non-euro countries UK and Sweden), fight against terrorism and against trade in and exploitation of human beings.

It seems therefore that such stated preferences by European citizens on the allocation of powers between the European level and the national level follows to some extent the predictions of the theory on fiscal federalism. Moreover, for many of these issues the preference for centralisation may stem from EU citizens' belief that coordination at EU level may help facing the rapid changes brought about by the process of globalisation (Ahrens et al., 2004). 
Graph 2: Mean preferences - Average 1995-2003 by country

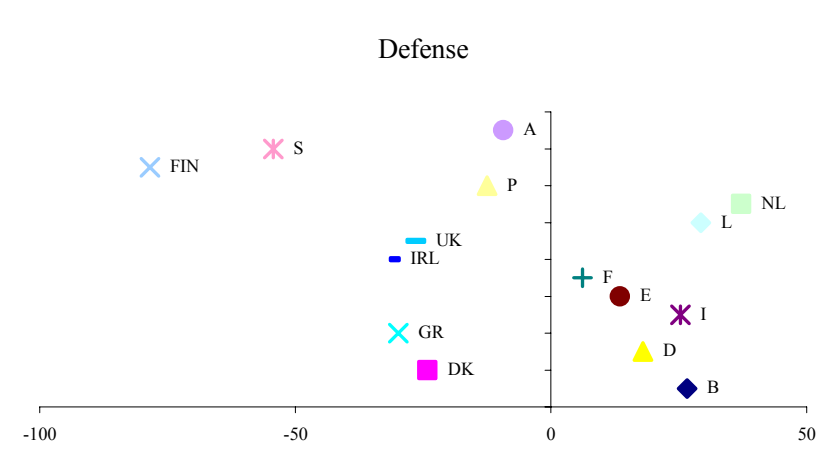

Environment

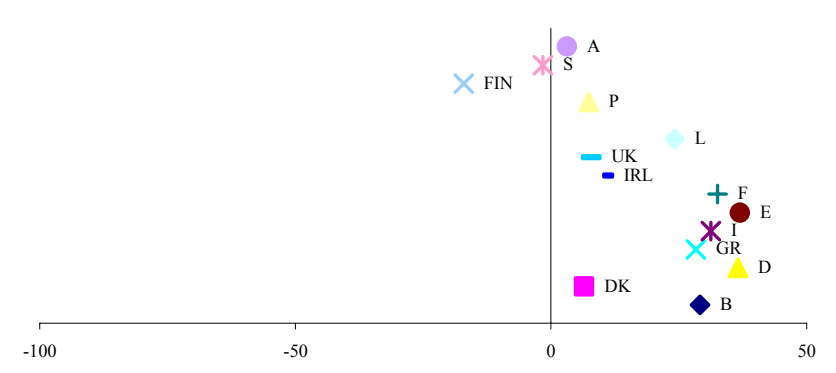

Humanitarian aid

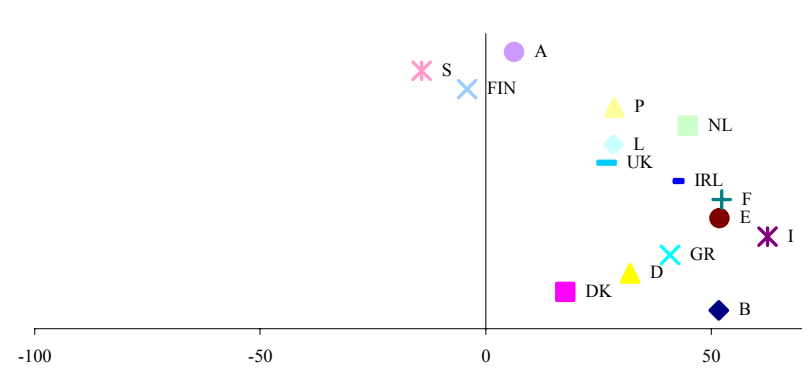

Media

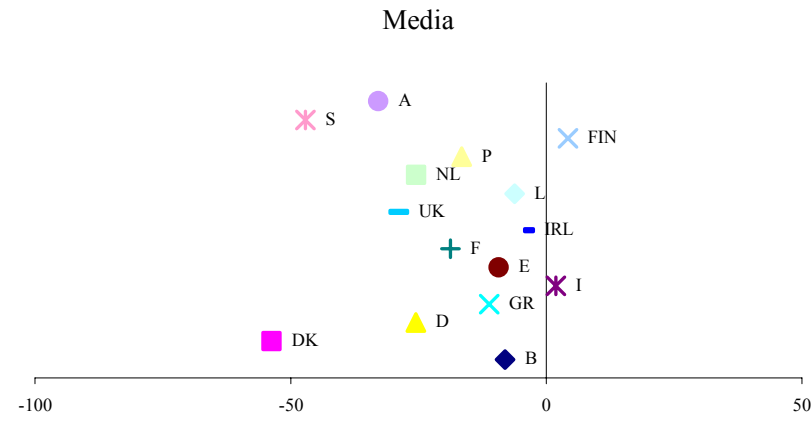

Currency

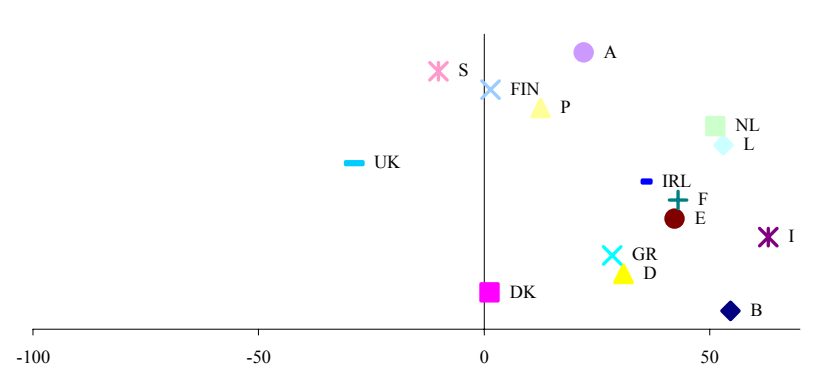

Health and social welfare

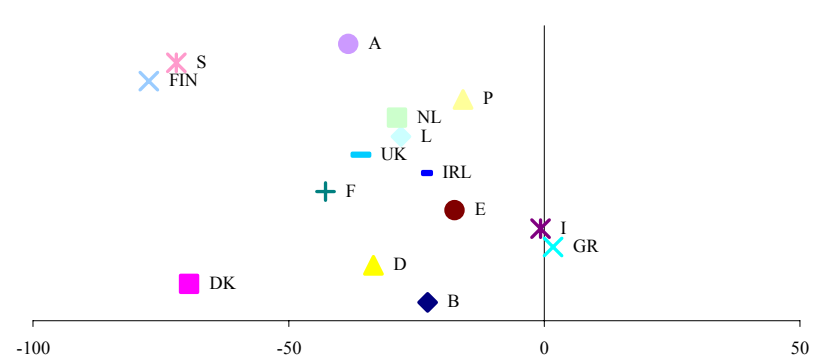

Education

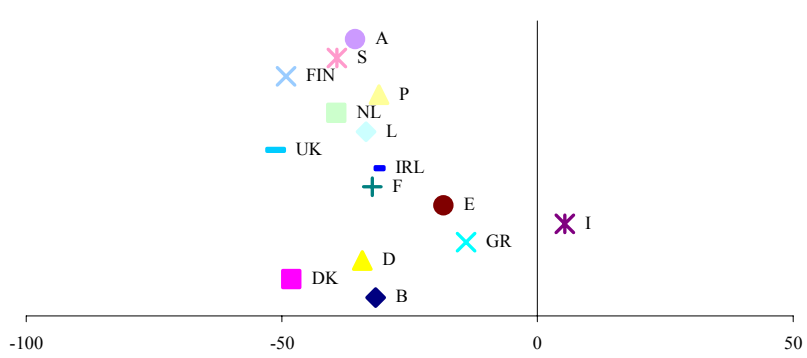

Poverty and social exclusion

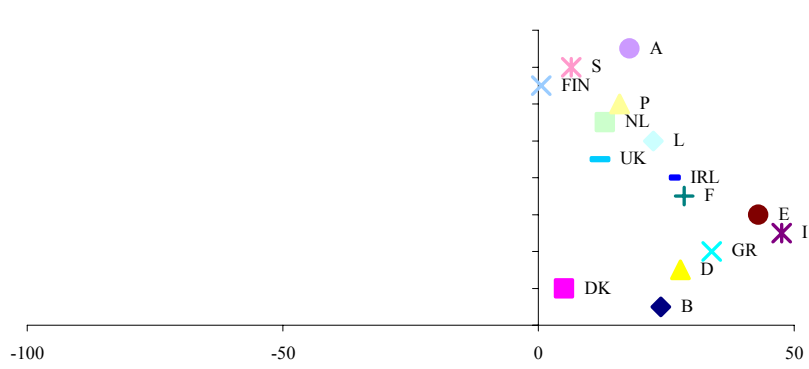

Research

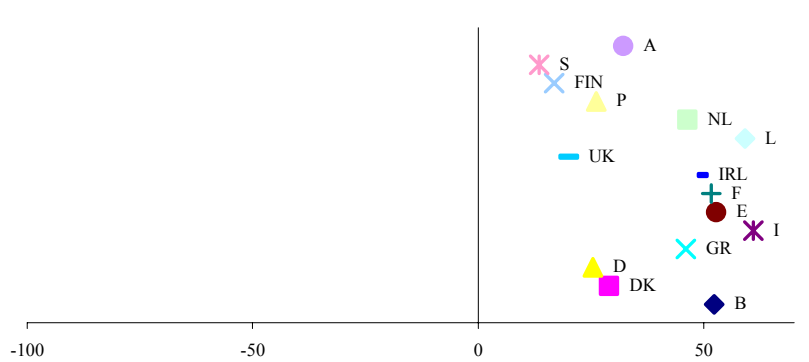


Graph 2: Mean preferences - Average 1995-2003 by country (continued)

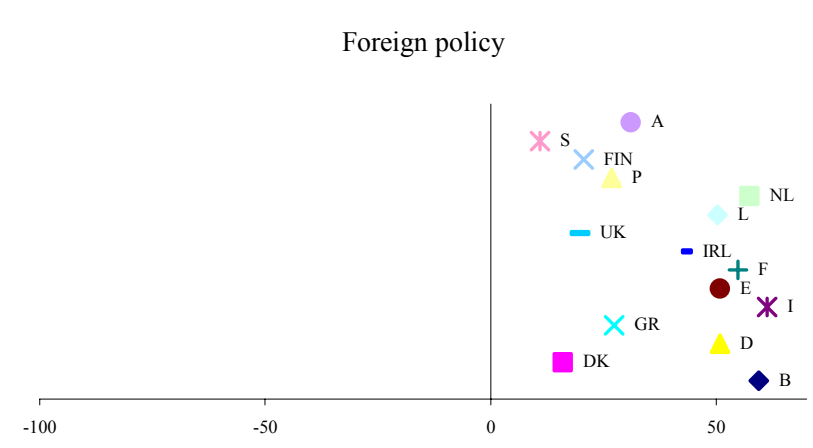

Political asylum

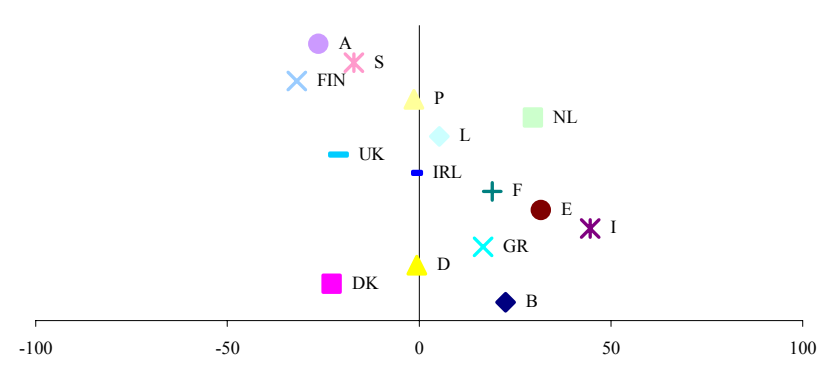

Agricolture

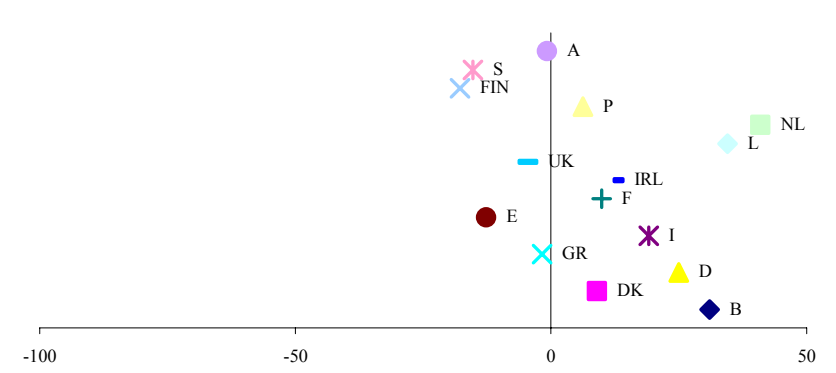

Culture

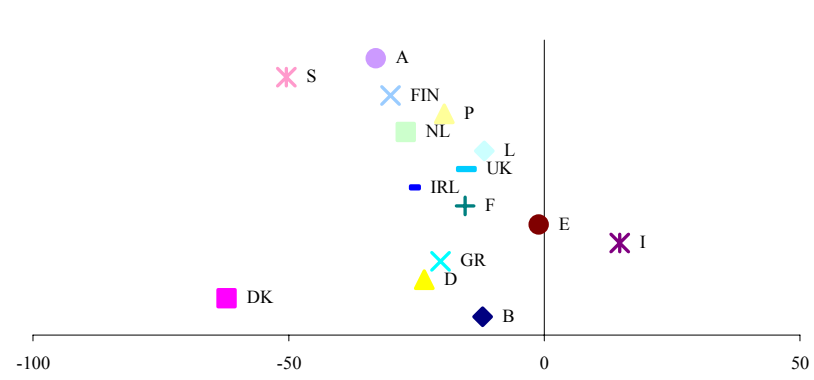

Unemployment

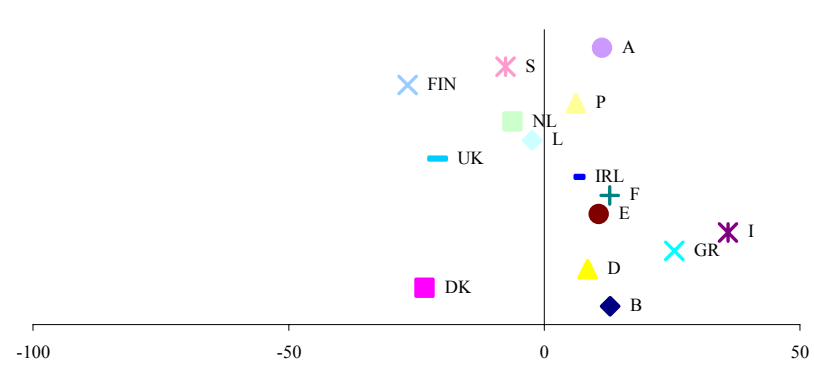

Regional aid

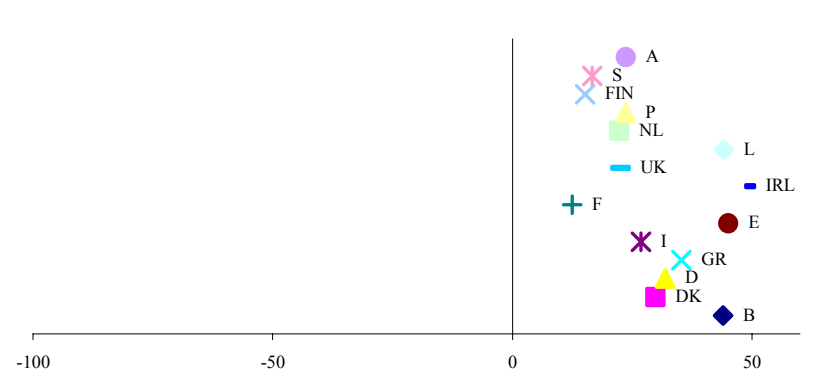

Immigration

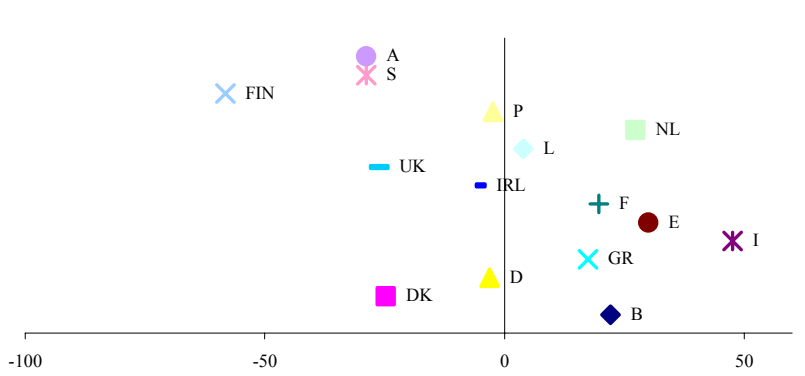

Drugs

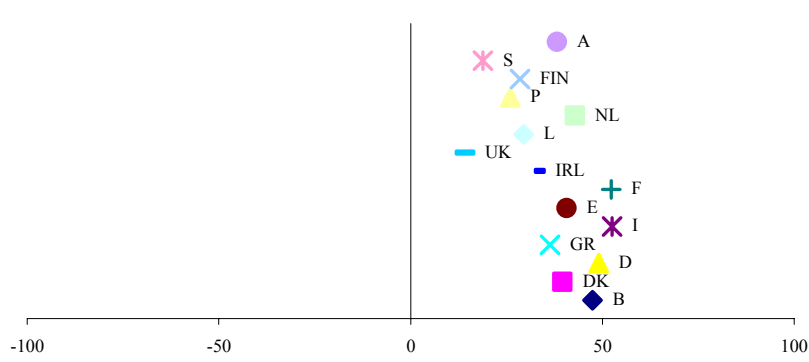

Infromation EU

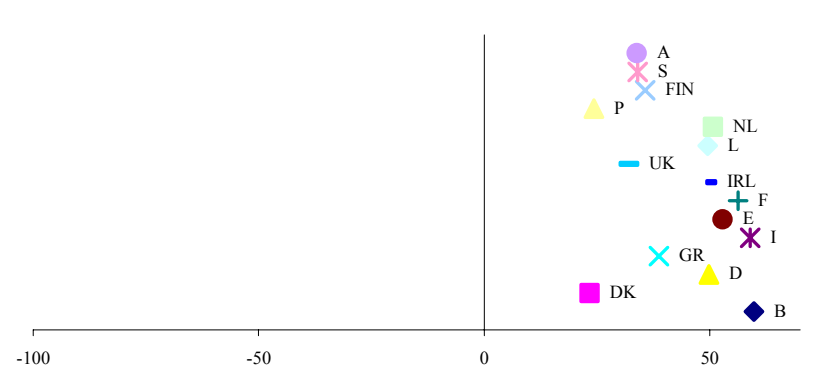


Graph 2: Mean preferences - Average 1995-2003 by country (continued)
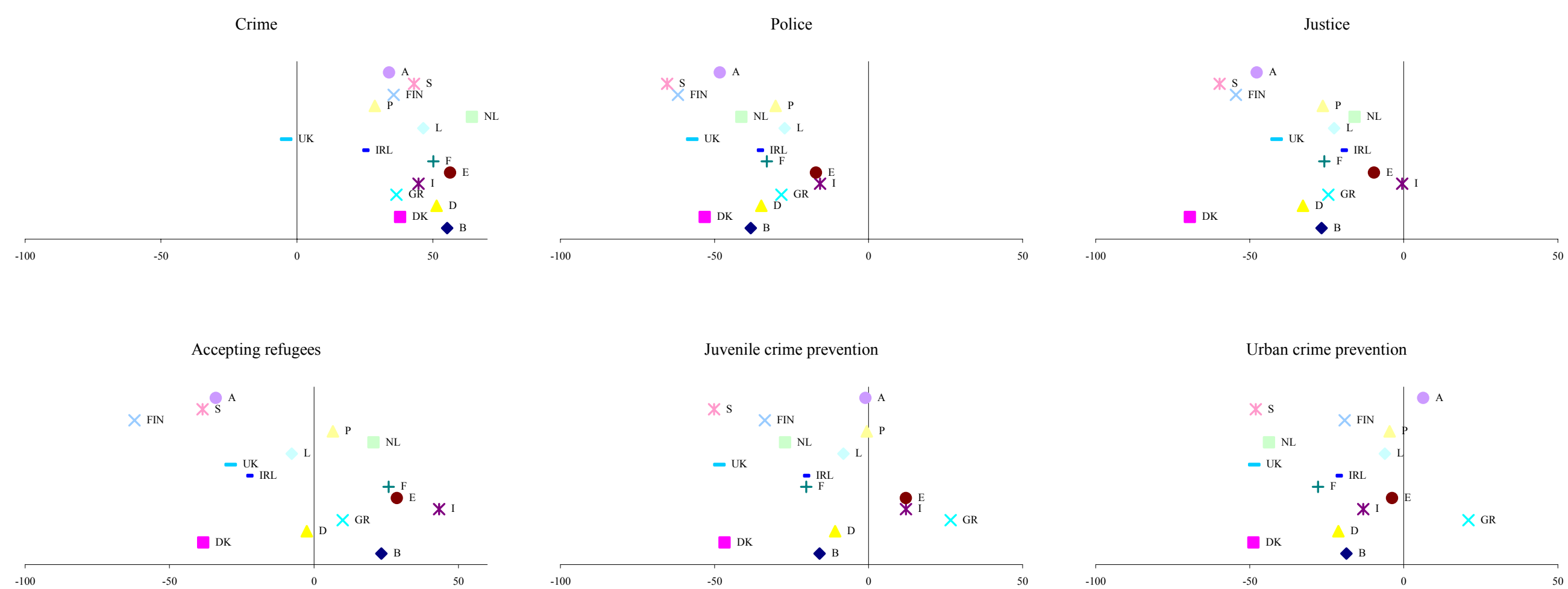

Fight against exploitation of human beings

Fight against terrorism

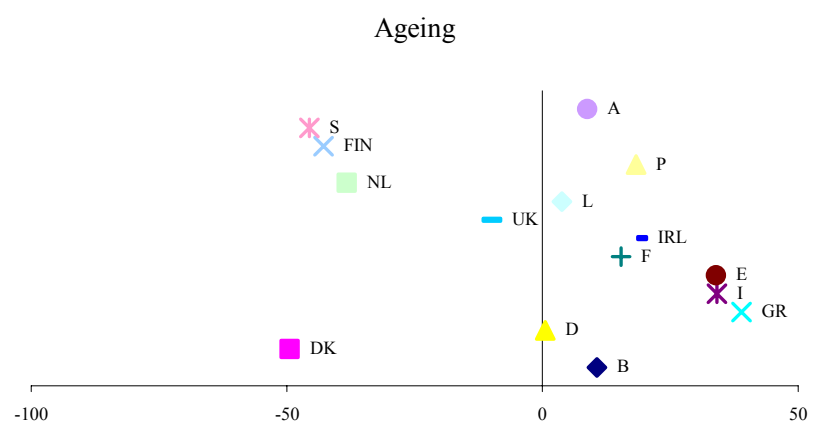


On the other side, for some policy areas such as justice, police, health and social welfare (with exception of Greece), media (with exception of Finland and Italy), cultural policy and education (with exception of Italy), all member states strongly agree to allocate the relative competences to the national level. A potential explanation for this result with regard to cultural policy, media and education lies in the citizens' will to defend own country national identity. Finally, there are some policy areas where the outcome is not so clear-cut and we observe great heterogeneity among countries. These are for example defence, immigration, accepting refugees and rules for political asylum, fight against unemployment and agriculture.

To conclude, Graphs 1 and 2 depict interesting results pointing out a ranking of countries according to their level of Europeanism, and a quite clear pattern of preferences relative to competence allocation for specific policy domains. However, these are only descriptive and average results. The next step is to investigate determinants and socio-economic factors driving European citizens' preferences towards the assignment of competences between the EU and member States. This is the aim of the next section.

\section{Econometric analysis}

Descriptive analysis provided in Section 4 suggests that some countries, independently of the policy domain, are always in favour of a shared responsibility within the EU; this can be interpreted as a preference toward the assignment of a function at the EU level (preference for centralization). On the other hand, we have also observed other countries always preferring decentralisation or a national competence. The aim of this section is to investigate whether there are other factors (beyond country) explaining preferences for centralization and decentralization

\subsection{Who is more pro-Europeanist?}

First of all, we estimate a sort of "degree of Europeanism" of European citizens. In order to do so, we build a variable stating the number of domains for which the respondent thinks the corresponding policy decisions should be taken jointly within the European Union. Thus, the higher the value of this variable, the higher the number of policy areas the respondent would like to allocate to European institutions.

We regress this variable on a number of individual characteristics, including demographic information and various indicators of the attitude towards EU. In order to exploit the whole sample, we start estimating a model containing the variables present in all the surveys (model 1). Then, we use different models (specifications) and replicate estimations on different sub samples in order to analyse the impact of variables included only in some editions of the Eurobarometer survey. More 
specifically, when we add a certain regressor, we perform estimation using the survey containing the maximum overall number of explanatory variables.

Moreover, we use 5 different dependent variables: the first is built considering the 16 policy domains present since the first survey (we call it EU43.1), the second, called EU50, consider the domains present since survey 50, and so on. The maximum number of considered domains is 27 (dependent variable EU57). In this case the largest sample (model 1) contains survey 57, 58, 59 and 60. Estimation is by OLS and results are in Tables 3-7; a negative coefficient indicates a negative impact of the correspondent variable on the degree of "Europeanism". Note that in the first specification (with estimation based on the smallest set of independent variables but on the largest sample) the year dummy are not statistically significant, pointing at no time effect on European citizens' preferences. Thus, our results suggest that the attitude towards competence allocation is basically constant over the time span we considered (1995-2003) despite the several actions taken in this period by EU.

Let us start from the models using EU43.1 as dependent variable (16 domains considered). In the first specification, which is estimated on the whole sample (209,469 observations), almost all explanatory variables are highly statistically significant. As emerged from descriptive analysis, there are clear-cut country patterns in the level of Europeanism: bearing in mind that Italy is the excluded category, the negative sign and the statistical significance of all country coefficients indicate that, even after controlling for demographic and other individual characteristics, Italy is the more pro-European country among EU15. Looking at the dimension of these coefficients, a ranking among countries emerges: the less pro-European countries are those in Scandinavia (Finland and Sweden), Denmark and Luxemburg; countries from Anglo-Saxon Europe (Ireland and UK), The Netherlands and Austria follow next. The third group is made up of France and Germany, which exhibit a higher degree of Europeanism, while the more pro-European countries are those from Southern Europe (Portugal, Spain, Greece and Italy) and Belgium.

Looking at results stemming from different specifications (model 2 to model 5, with estimation based on one single Eurobarometer survey), results by countries are generally confirmed; in some specifications, the differences between Italy and Greece and between Italy and Spain are not statistically significant. The same ranking is also generally maintained when the models are estimated on the other dependent variables (EU50, EU52, EU56 and EU57), that is those considering larger sets of policy domains. Note that with the increase in the number of areas, sample size decreases and refers progressively to more recent years. Interestingly, in most cases the absolute values of the country coefficients increase with the number of domains used to build the dependent variable (and, consequently, with time), pointing to an increasing distance of EU countries from Italy in the degree of "Europeanism". 
Table 3: Dependent variable EU43 (Europeanism on 16 domains)

\begin{tabular}{|c|c|c|c|c|c|}
\hline Variable & model $1^{\mathrm{a}}$ & $\operatorname{model} 2^{\mathrm{b}}$ & model $3^{\mathrm{c}}$ & $\operatorname{model} 4^{\mathrm{d}}$ & model $5^{\mathrm{e}}$ \\
\hline \multicolumn{6}{|l|}{$\begin{array}{l}\text { Country (ref. Italy) } \\
\text { (t) }\end{array}$} \\
\hline France & $-1.255 * * *$ & $-1.5 * * *$ & $-1.01 * * *$ & $-1.52 * * *$ & $-0.71 * * *$ \\
\hline Belgium & $-1.017 * * *$ & $-1.09 * * *$ & -0.05 & $-1.52 * * *$ & $-0.66 * * *$ \\
\hline The Netherlands & $-2.049 * * *$ & $-2.42 * * *$ & $-1.06 * * *$ & $-2.48 * * *$ & $-1.31 * * *$ \\
\hline Germany & $-1.217 * * *$ & $-1.65 * * *$ & $-1.58 * * *$ & $-1.74 * * *$ & $-1 * * *$ \\
\hline Luxemburg & $-3.267 * * *$ & $-2.68 * * *$ & $-2.22 * *$ & $-2.21 * *$ & $-3.01 * * *$ \\
\hline Denmark & $-3.476 * * *$ & $-4.04 * * *$ & $-3.47 * * *$ & $-4.32 * * *$ & $-3.16 * * *$ \\
\hline Ireland & $-2.196 * * *$ & $-3.08 * * *$ & $-2.48 * * *$ & $-2.31 * * *$ & $-1.51 * * *$ \\
\hline UK & $-2.406 * * *$ & $-2.49 * * *$ & $-2.74 * * *$ & $-2.32 * * *$ & $-1.6 * * *$ \\
\hline Greece & $-0.222 * * *$ & -0.14 & $-1.07 * * *$ & $-1.19 * * *$ & 0.201 \\
\hline Spain & $-0.469 * * *$ & $-0.63 * * *$ & $-0.57 * * *$ & 0.004 & -0.07 \\
\hline Portugal & $-1.024 * * *$ & $-3.48 * * *$ & $-2.59 * * *$ & $-2.01 * * *$ & $-0.5 * *$ \\
\hline Finland & $-3.837 * * *$ & $-4.01 * * *$ & $-3.82 * * *$ & $-3.89 * * *$ & $-3.6 * * *$ \\
\hline Sweden & $-3.35 * * *$ & $-3.54 * * *$ & $-2.78 * * *$ & $-4.12 * * *$ & $-3.27 * * *$ \\
\hline Austria & $-2.342 * * *$ & $-2.95 * * *$ & $-1.97 * * *$ & $-2.87 * * *$ & $-2.16 * * *$ \\
\hline female & $-0.225 * * *$ & -0.06 & $-0.16 * *$ & -0.03 & -0.08 \\
\hline \multicolumn{6}{|l|}{ age (ref. age > 64) } \\
\hline age $15-24$ & $0.0992 * *$ & 0.061 & $0.647 * * *$ & $0.75^{* * *}$ & 0.052 \\
\hline age $25-34$ & $0.3027 * * *$ & -0.21 & $0.859 * * *$ & $0.572 * * *$ & 0.193 \\
\hline age $35-44$ & 0.0147 & -0.07 & $0.733 * * *$ & $0.634 * * *$ & -0.12 \\
\hline age $45-54$ & $0.2864 * * *$ & 0.067 & $0.853 * * *$ & $0.491 * * *$ & 0.129 \\
\hline age $55-64$ & $0.2848 * * *$ & 0.117 & $0.589 * * *$ & $0.243 *$ & 0.179 \\
\hline household head & -0.015 & $0.325 * * *$ & $0.228 * *$ & $0.2 * *$ & 0.075 \\
\hline married/parnered & $0.2378 * * *$ & 0.09 & 0.047 & -0.06 & 0.102 \\
\hline \multicolumn{6}{|l|}{ education (ref. stop education before/at 15) } \\
\hline stop education between 16 and 19 & $0.4334 * * *$ & $0.192 * *$ & $0.283 * * *$ & $-0.24 * * *$ & $0.272 * * *$ \\
\hline stop education after 20 & $0.7002 * * *$ & $0.404 * * *$ & 0.149 & 0.084 & $0.356 * * *$ \\
\hline \multicolumn{6}{|c|}{ labour market position (ref. high skilled white collars) } \\
\hline housekeeper & $-0.539 * * *$ & 0.169 & 0.056 & $0.457 * * *$ & -0.24 \\
\hline student & $-0.203 * * *$ & 0.288 & $0.558 * * *$ & -0.2 & -0.23 \\
\hline unemployed & $-0.454 * * *$ & $0.419 * *$ & 0.196 & 0.141 & -0.04 \\
\hline retired & $-0.313 * * *$ & $-0.4 * *$ & 0.121 & 0.073 & -0.06 \\
\hline farmer/fisherman & $-0.72 * * *$ & 0.048 & $1.272 * * *$ & 0.583 & -0.32 \\
\hline professional & $0.136 *$ & 0.134 & 0.128 & -0.23 & 0.119 \\
\hline business proprietor & $-0.362 * * *$ & 0.15 & 0.212 & 0.243 & -0.23 \\
\hline low skill white-collar & $-0.295 * * *$ & 0.164 & $0.237 *$ & 0.019 & -0.1 \\
\hline blue-collar & $-0.357 * * *$ & 0.077 & 0.078 & 0.136 & -0.04 \\
\hline \multicolumn{6}{|l|}{ political affiliation (ref. left) } \\
\hline political affiliation: right & $-0.784 * * *$ & $-0.57 * * *$ & $-0.34 * * *$ & $-0.49 * * *$ & $-0.63 * * *$ \\
\hline political affiliation: centre & $-0.201 * * *$ & -0.1 & $0.16 *$ & -0.06 & $-0.15 *$ \\
\hline political affiliation: $\mathrm{dk}$ & $-0.721 * * *$ & $-0.64 * * *$ & $-0.55 * * *$ & $-0.27 * * *$ & $-0.27 * * *$ \\
\hline \multicolumn{6}{|l|}{ attitude twd membership (ref. bad) } \\
\hline attitude twd membership: good & $3.8466 * * *$ & $2.85 * * *$ & $3.336 * * *$ & $2.351 * * *$ & $2.696 * * *$ \\
\hline attitude twd membership: neutral & $2.2164 * * *$ & $1.628 * * *$ & $2.139 * * *$ & $1.419^{* * *}$ & $1.654 * * *$ \\
\hline attitude twd membership: $\mathrm{dk}$ & $0.5007 * * *$ & $0.841 * * *$ & $1.579 * * *$ & $0.626 * * *$ & $0.439 * * *$ \\
\hline \multicolumn{6}{|l|}{ country benefited from $E U$ (ref. no) } \\
\hline think own country benefited from EU: yes & $1.1803 * * *$ & $0.601 * * *$ & $0.649 * * *$ & $0.589 * * *$ & $0.672 * * *$ \\
\hline think own country benefited from EU: $\mathrm{dk}$ & $-0.131 * * *$ & -0.14 & 0.021 & 0.061 & -0.13 \\
\hline \multicolumn{6}{|l|}{ year (ref. year 2003) } \\
\hline year 1995 & 0.938 & & & & \\
\hline year 1997 & 0.2659 & & & & \\
\hline year 1998 & 0.4056 & & & & \\
\hline year 1999 & -0.16 & & & & \\
\hline year 2000 & -0.164 & & & & \\
\hline year 2001 & 0.2535 & & & & \\
\hline year 2002 & -0.029 & & & & \\
\hline
\end{tabular}

Variable

EU knowledge

feel more (ref. European)

feel more: own nationality

feel more: don't know

life satisfaction (ref. low

life satisfaction: high

life satisfaction: medium-high

life satisfaction: medium-low

life satisfaction: $\mathrm{dk}$

democracy satisfaction (own country) (ref. low)

democracy satisfaction (own country): high

democracy satisfaction (own country): medium-high

democracy satsaction (own country): medium-low

democracy satisfaction (own country):

democracy salisfaction (LU) (ref.low):

democracy satisfaction (EU): medium-high

democracy satisfaction (EU): medium-low

democracy satisfaction (EU): $\mathrm{dk}$

tv frequency

newspaper frequen

radio frequency

income (ref. forth quartile)

first income quartile

second income quartile

third income quartile

area of living (ref. rurat)

area of living (ree. rural)

area of ling. large town

area of living: $\mathrm{dk}$

proud to be of own nationality (ref. low

proud to be of own nationality: high

proud to be of own nationality: medium-high

proud to be of own nationlity medium-low

proud to be of own nationality: dk

proud to be European (ref. low)

proud to be European: high

proud to be European: medium-high
proud to be European: medium-low

proud to be European: $\mathrm{dk}$

religion (ref. no religion)

cristian

other religion

personal advantage from membership (ref. low)

personal advantage from membership: high

personal advantage from membership: $\mathrm{dk}$

probability to vote (national election)

probability to vote

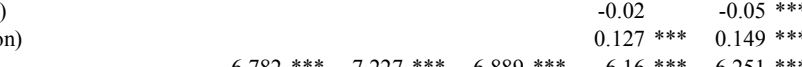

\begin{tabular}{lccccc} 
Constant & $6.782 * * *$ & $7.227 * * *$ & $6.889 * * *$ & $6.16 * * *$ & $6.251 * * *$ \\
\hline Number of obs & 209469 & 15939 & 16155 & 16012 & 16070 \\
Prob $>$ F & 0.000 & 0.000 & 0.000 & 0.000 & 0.000
\end{tabular}

Prob $>$ F

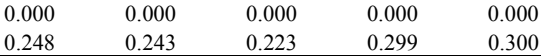

legend: * $\mathbf{p}<.1 ; * * \mathbf{p}<.05 ; * * * \mathrm{p}<.01$

a: estimated on all surveys; b: estimated on survey 56 ; c: estimated on survey 50 ; d: estimated on survey 57 ; e: estimated on survey 60 . 
Table 4: Dependent variable EU50 (Europeanism on 18 domains)

\begin{tabular}{|c|c|c|c|c|c|}
\hline Variable & model $1^{\mathrm{a}}$ & $\operatorname{model} 2^{\mathrm{b}}$ & model $3^{\mathrm{c}}$ & model $4^{\mathrm{d}}$ & model $5^{\mathrm{e}}$ \\
\hline \multicolumn{6}{|l|}{ Country (ref. Italy) } \\
\hline France & $-1.367 * * *$ & $-1.64 * * *$ & $-1.05 * * *$ & $-1.63 * * *$ & $-0.76 * * *$ \\
\hline Belgium & $-1.193 * * *$ & $-1.21 * * *$ & -0.13 & $-1.72 * * *$ & $-0.77^{* * *}$ \\
\hline The Netherlands & $-2.371 * * *$ & $-2.8 * * *$ & $-1.29 * * *$ & $-2.79 * * *$ & $-1.54 * * *$ \\
\hline Germany & $-1.308 * * *$ & $-1.76^{* * *}$ & $-1.7 * * *$ & $-1.86^{* * *}$ & $-1.05 * * *$ \\
\hline Luxemburg & $-3.694 * * *$ & $-2.96 * * *$ & $-2.48 * *$ & $-2.43 * *$ & $-3.37 * * *$ \\
\hline Denmark & $-3.96 * * *$ & $-4.47^{* * *}$ & $-3.88 * * *$ & $-4.74^{* * *}$ & $-3.61 * * *$ \\
\hline Ireland & $-2.419 * * *$ & $-3.34 * * *$ & $-2.69 * * *$ & $-2.51 * * *$ & $-1.65 * * *$ \\
\hline UK & $-2.586 * * *$ & $-2.65 * * *$ & $-2.93 * * *$ & $-2.53 * * *$ & $-1.67 * * *$ \\
\hline Greece & $-0.273 * * *$ & -0.19 & $-1.14 * * *$ & $-1.33^{* * *}$ & 0.185 \\
\hline Spain & $-0.524 * * *$ & $-0.69 * * *$ & $-0.57 * * *$ & 0.012 & -0.07 \\
\hline Portugal & $-1.2 * * *$ & $-3.95 * * *$ & $-2.89 * * *$ & $-2.34^{* * *}$ & $-0.63 * * *$ \\
\hline Finland & $-4.218 * * *$ & $-4.34 * * *$ & $-4.12 * * *$ & $-4.16 * * *$ & $-3.97 * * *$ \\
\hline Sweden & $-3.622 * * *$ & $-3.78 * * *$ & $-3.06 * * *$ & $-4.39 * * *$ & $-3.53 * * *$ \\
\hline Austria & $-2.576 * * *$ & $-3.18^{* * *}$ & $-2.15 * * *$ & $-3.14^{* * *}$ & $-2.37 * * *$ \\
\hline female & $-0.226 * * *$ & -0.09 & $-0.17 *$ & -0.04 & -0.06 \\
\hline \multicolumn{6}{|l|}{ age (ref. age > 64) } \\
\hline age $15-24$ & $0.1337 * *$ & 0.128 & $0.76^{* * *}$ & $0.864^{* * *}$ & 0.09 \\
\hline age $25-34$ & $0.3833 * * *$ & -0.16 & $0.964 * * *$ & $0.638^{* * * *}$ & $0.266 *$ \\
\hline age $35-44$ & 0.055 & -0.02 & $0.828 * * *$ & $0.718^{* * *}$ & -0.1 \\
\hline age $45-54$ & $0.3499 * * *$ & 0.1 & $0.948 * * *$ & $0.54 * * *$ & 0.177 \\
\hline age $55-64$ & $0.3636 * * *$ & 0.172 & $0.707^{* * *}$ & $0.279 *$ & $0.246 *$ \\
\hline household head & -0.02 & $0.349^{* * *}$ & $0.251 * *$ & $0.219 * *$ & 0.076 \\
\hline married/parnered & $0.282 * * *$ & 0.093 & 0.063 & -0.04 & 0.128 \\
\hline \multicolumn{6}{|l|}{ education (ref. stop education before/at 15) } \\
\hline stop education between 16 and 19 & $0.5095 * * *$ & $0.187 *$ & $0.342 * * *$ & $-0.25 * *$ & $0.328 * * *$ \\
\hline stop education after 20 & $0.7874 * * *$ & $0.426 * * *$ & $0.221 *$ & 0.106 & $0.403 * * *$ \\
\hline \multicolumn{6}{|c|}{ labour market position (ref. high skilled white collars) } \\
\hline housekeeper & $-0.644 * * *$ & 0.201 & 0.016 & $0.5 * * *$ & $-0.31 *$ \\
\hline student & $-0.186 * * *$ & 0.334 & $0.648 * * *$ & -0.16 & -0.22 \\
\hline unemployed & $-0.521 * * *$ & $0.484 * *$ & 0.152 & 0.203 & -0.06 \\
\hline retired & $-0.348 * * *$ & $-0.44 * *$ & 0.064 & 0.052 & -0.07 \\
\hline farmer/fisherman & $-0.777 * * *$ & 0.12 & $1.419^{* * *}$ & 0.615 & -0.33 \\
\hline professional & 0.0929 & 0.103 & 0.118 & -0.32 & 0.084 \\
\hline business proprietor & $-0.413 * * *$ & 0.142 & 0.267 & $0.354 *$ & -0.26 \\
\hline low skill white-collar & $-0.296 * * *$ & 0.206 & $0.285 *$ & 0.061 & -0.08 \\
\hline blue-collar & $-0.392 * * *$ & 0.059 & 0.075 & 0.166 & -0.04 \\
\hline \multicolumn{6}{|l|}{ political affiliation (ref. left) } \\
\hline political affiliation: right & $-0.876 * * *$ & $-0.65 * * *$ & $-0.39 * * *$ & $-0.55 * * *$ & $-0.7^{* * *}$ \\
\hline political affiliation: centre & $-0.179 * * *$ & -0.08 & $0.184 * *$ & -0.08 & -0.13 \\
\hline political affiliation: $\mathrm{dk}$ & $-0.808 * * *$ & $-0.74 * * *$ & $-0.63 * * *$ & $-0.31 * * *$ & $-0.29 * * *$ \\
\hline \multicolumn{6}{|l|}{ attitude twd membership (ref. bad) } \\
\hline attitude twd membership: good & $4.2972 * * *$ & $3.281 * * *$ & $3.726^{* * *}$ & $2.673^{* * *}$ & $2.998 * * *$ \\
\hline attitude twd membership: neutral & $2.4735 * * *$ & $1.922 * * *$ & $2.38 * * *$ & $1.605 * * *$ & $1.83 * * *$ \\
\hline attitude twd membership: dk & $0.5002 * * *$ & $0.968 * * *$ & $1.688 * * *$ & $0.677^{* * *}$ & $0.44 * *$ \\
\hline \multicolumn{6}{|l|}{ country benefited from EU (ref. no) } \\
\hline think own country benefited from EU: yes & $1.3117 * * *$ & $0.646 * * *$ & $0.706 * * *$ & $0.616 * * *$ & $0.746 * * *$ \\
\hline think own country benefited from EU: $\mathrm{dk}$ & $-0.189 * * *$ & $-0.2 *$ & 0.004 & 0.023 & -0.18 \\
\hline \multicolumn{6}{|l|}{ year (ref. year 2003) } \\
\hline year 1998 & 0.4615 & & & & \\
\hline year 1999 & -0.143 & & & & \\
\hline year 2000 & -0.125 & & & & \\
\hline year 2001 & 0.3404 & & & & \\
\hline year 2002 & 0.0189 & & & & \\
\hline EU knowledge & & $0.12 * * *$ & $0.195 * * *$ & $0.126 * * *$ & \\
\hline
\end{tabular}

\section{Variable}

feel more (ref. European)

feel more: don't know

life satisfaction (ref. low)

life satisfaction: high

life satisfaction: medium-high

life satisfaction: medium-low

life satisfaction: $\mathrm{dk}$

democracy satisfaction (own country) (ref. low)

democracy satisfaction (own country): high

democracy satisfaction (own country): medium-high

democracy satistaction (own country): medium-low

democracy satisfaction (own country): d

democracy satisfaction (EU) (ref. lon)

democracy satisfaction (EU): high
democracy satisfaction (EU): medium-high

democracy satisfaction (EU): medium-low

democracy satisfaction (EU): $\mathrm{dk}$

tv frequency

newspaper frequency

radio frequency

income (ref. forth quartile)

first income quartile

second income quartile

third income quartile

undeclared income

area of living (ref. rural)

area of living. large town

area of living: $\mathrm{dk}$

proud to be of own nationality (ref. low

proud to be of own nationality: high

proud to be of own nationality: medium-high

proud to be of own nationality: medium-low

proud to be of own nationality: $\mathrm{dk}$

proud to be European (ref. low)

proud to be European: high

proud to be European: medium-high

proud to be European: medium-low

proud to be European: $\mathrm{dk}$

religion (ref. no religion)

cristian

other religion

personal advantage from membership (ref. low)

personal advantage from membership: high

personal advantage from membership: $\mathrm{dk}$

probability to vote (national election)

\begin{tabular}{lllll}
$\operatorname{model~} 1^{\mathrm{a}}$ & $\operatorname{model~}^{\mathrm{b}}$ & model $^{\mathrm{c}}$ & $\operatorname{model} 4^{\mathrm{d}}$ & $\operatorname{model} 5^{\mathrm{e}}$ \\
\hline
\end{tabular}

$\begin{array}{lrr}-0.68 * * * & -1.4 * * * & -0.88 * * * \\ -1.44 * * * & -2.49 * * * & -1.24 * * *\end{array}$

$0.023 \quad 0.939 * * *$

$\begin{array}{ll}-0.21 & 0.966 * * * \\ -0.39 & 0.751 *\end{array}$

$\begin{array}{lc}-0.39 & 0.751 * * * \\ -1.42 * * * & -0.5\end{array}$

$-0.61 * * *$

$-0.46 * *$

-0.84 ***

$1.049 * *$

$0.744 * * *$

$0.535 * * *$

$0.176 \quad 0.193 *$

$0.075 \quad 0.103$

$0.08 \quad 0.335 * *$

$-0.34 * * \quad-0.81 * * * \quad-0.47 * * *$

$\begin{array}{lll}-0.07 & -0.15 & -0.2 \\ -0.25 * & -0.25 * * & -0.16\end{array}$

$\begin{array}{lll}-0.25 * & -0.25 * * & -0.16 \\ -0.33 * * & -0.71 * * & -0.48 * *\end{array}$

$0.098 \quad 0.267 * * * 0.09$

$0.158 * 0.329 * * * \quad-0.18 *$

$-0.77-0.076$

$\begin{array}{ll}-1.61 * * * & -2.46 * * * \\ -1.21 * * * & -1.78 * * *\end{array}$

$\begin{array}{rr}-1.21 * * * & -1.78 * * * \\ -1 * * * & -0.8 * * * \\ -0.94 * * & -1.65 * *\end{array}$

$-0.94 * * * \quad-0.8 * * *$

$2.615 * * * \quad 2.806 * * *$

$2.293 * * * \quad 2.283 * * *$

$\begin{array}{ll}1.583 * * * & 1.253 * * * \\ 1.49 * * * & 1.291^{* * *}\end{array}$

\begin{tabular}{|c|c|c|c|c|c|}
\hline probability to vote (European election) & & & & $0.141^{* * *}$ & \\
\hline Constant & $7.7928 * * *$ & $8.273 * * *$ & $7.943 * * *$ & & \\
\hline Number of obs & 160952 & 15939 & 16155 & 16012 & 16070 \\
\hline Prob $>$ F & 0.000 & 0.000 & 0.000 & 0.000 & 0.000 \\
\hline R-squared & 0.245 & 0.242 & 0.222 & 0.297 & 0.297 \\
\hline
\end{tabular}

legend: * $\mathrm{p}<1 ;{ }^{* *} \mathrm{p}<.05 ; * * * \mathrm{p}<.01$

a: estimated on all surveys after 49; b: estimated on survey 56 ; c: estimated on survey 50 ; d: estimated on survey 57 ; e: estimated on survey
$1.535 * * *$

$1.074 * * *$

$0.419 * *$

$-0.01$

16070 


\begin{tabular}{|c|c|c|c|c|}
\hline Variable & model $1^{\mathrm{a}}$ & model $2^{\mathrm{b}}$ & $\operatorname{model} 4^{\mathrm{c}}$ & model $5^{\mathrm{d}}$ \\
\hline \multicolumn{5}{|l|}{ feel more (ref. European) } \\
\hline feel more: own nationality & & $-0.89 * * *$ & $-1.402 * * *$ & $-1.346 * * *$ \\
\hline feel more: don't know & & $-1.883 * * *$ & $-1.848 * * *$ & $-1.021 * * *$ \\
\hline \multicolumn{5}{|l|}{ life satisfaction (ref. low) } \\
\hline life satisfaction: high & & -0.032 & $1.3205 * * *$ & $0.5711 * *$ \\
\hline life satisfaction: medium-high & & -0.239 & $1.3981 * * *$ & $0.8511^{* * *}$ \\
\hline life satisfaction: medium-low & & -0.465 & $1.1742 * * *$ & $1.0022 * * *$ \\
\hline life satisfaction: $\mathrm{dk}$ & & $-1.9 * * *$ & -0.679 & -0.641 \\
\hline \multicolumn{5}{|l|}{ democracy satisfaction (own country) (ref. low) } \\
\hline democracy satisfaction (own country): high & & $-0.93 * * *$ & & $-0.82 * * *$ \\
\hline democracy satisfaction (own country): medium-high & & $-0.812 * * *$ & & $-0.555 * * *$ \\
\hline democracy satisfaction (own country): medium-low & & $-0.501 * *$ & & $-0.32 *$ \\
\hline democracy satisfaction (own country): dk & & $-1.473 * * *$ & & $-1.913 * * *$ \\
\hline \multicolumn{5}{|l|}{ democracy satisfaction (EU) (ref. low) } \\
\hline democracy satisfaction (EU): high & & $1.4465 * * *$ & & $1.884 * * *$ \\
\hline democracy satisfaction (EU): medium-high & & $1.8402 * * *$ & & $2.2253 * * *$ \\
\hline democracy satisfaction (EU): medium-low & & $1.0371 * * *$ & & $1.2729 * * *$ \\
\hline democracy satisfaction (EU): dk & & $0.7656 * * *$ & & $1.1506 * * *$ \\
\hline tv frequency & & 0.2762 & & \\
\hline newspaper frequency & & 0.0445 & & \\
\hline radio frequency & & 0.1486 & & \\
\hline \multicolumn{5}{|l|}{ income (ref. forth quartile) } \\
\hline first income quartile & & $-0.474 * *$ & $-0.546 * * *$ & $-0.828 * * *$ \\
\hline second income quartile & & -0.082 & -0.294 & $-0.43 * *$ \\
\hline third income quartile & & $-0.337 *$ & -0.159 & -0.062 \\
\hline \multirow{2}{*}{\multicolumn{5}{|c|}{$\begin{array}{l}\text { area of living (ref. rural) } \\
\text { a }\end{array}$}} \\
\hline & & & & \\
\hline area of living: large town & & 0.1464 & -0.209 & -0.088 \\
\hline area of living: small town & & $0.2446 *$ & $-0.287 * *$ & -0.135 \\
\hline \multirow{2}{*}{\multicolumn{5}{|c|}{ proud to be of own nationality (ref. low) }} \\
\hline & & & & \\
\hline proud to be of own nationality: high & & $-2.317 * * *$ & $-3.29 * * *$ & $-2.628 * * *$ \\
\hline proud to be of own nationality: medium-high & & $-1.825 * * *$ & $-2.279 * * *$ & $-2.334 * * *$ \\
\hline proud to be of own nationality: medium-low & & $-1.481 * * *$ & $-1.054 * * *$ & $-1.548 * * *$ \\
\hline proud to be of own nationality: $\mathrm{dk}$ & & $-1.31 * * *$ & $-2.216 * * *$ & $-1.775 * * *$ \\
\hline \multicolumn{5}{|l|}{ proud to be European (ref. low) } \\
\hline proud to be European: high & & $3.5923 * * *$ & $3.8895 * * *$ & $3.5456 * * *$ \\
\hline proud to be European: medium-high & & $3.0992 * * *$ & $2.9786 * * *$ & $3.1506 * * *$ \\
\hline proud to be European: medium-low & & $2.0659 * * *$ & $1.6322 * * *$ & $1.3145 * * *$ \\
\hline proud to be European: dk & & $2.0054 * * *$ & $1.807 * * *$ & $1.3203 * * *$ \\
\hline \multirow{2}{*}{\multicolumn{5}{|c|}{$\begin{array}{l}\text { personal advantage from membership (ref. low) } \\
\text { personal advantage from membership: high }\end{array}$}} \\
\hline & & & $2.0782 * * *$ & \\
\hline personal advantage from membership: medium & & & $1.347 * * *$ & \\
\hline personal advantage from membership: $\mathrm{dk}$ & & & $0.4512 * *$ & \\
\hline probability to vote (national election) & & & -0.03 & $-0.069 * * *$ \\
\hline probability to vote (European election) & & & $0.2002 * * *$ & $0.2329 * * *$ \\
\hline Constant & $10.676 * * *$ & $11.568 * * *$ & $9.6149 * * *$ & $9.6422 * * *$ \\
\hline Number of obs & 128618 & 15939 & 16012 & 16070 \\
\hline Prob $>F$ & 0.000 & 0.000 & 0.000 & 0.000 \\
\hline R-squared & 0.240 & 0.232 & 0.294 & 0.294 \\
\hline
\end{tabular}

\begin{tabular}{|c|c|c|c|c|}
\hline Variable & model $1^{a}$ & $\operatorname{model} 2^{\mathrm{b}}$ & $\operatorname{model} 4^{c}$ & $\operatorname{model} 5^{\mathrm{d}}$ \\
\hline \multicolumn{5}{|l|}{ Country (ref. Italy) } \\
\hline France & $-1.881 * * *$ & $-2.137 * * *$ & $-2.236 * * *$ & $-1.027 * * *$ \\
\hline Belgium & $-1.889 * * *$ & $-1.713 * * *$ & $-2.585 * * *$ & $-1.304 * * *$ \\
\hline The Netherlands & $-3.217 * * *$ & $-3.476 * * *$ & $-3.951 * * *$ & $-2.062 * * *$ \\
\hline Germany & $-1.723 * * *$ & $-2.277 * * *$ & $-2.388 * * *$ & $-1.365 * * *$ \\
\hline Luxemburg & $-4.932 * * *$ & $-4.005 * * *$ & $-3.187 * *$ & $-4.526 * * *$ \\
\hline Denmark & $-5.438 * * *$ & $-6.152 * * *$ & $-6.418 * * *$ & $-4.871 * * *$ \\
\hline Ireland & $-3.391 * * *$ & $-4.518 * * *$ & $-3.523 * * *$ & $-2.311 * * *$ \\
\hline UK & $-3.862 * * *$ & $-3.751 * * *$ & $-3.607 * * *$ & $-2.588 * * *$ \\
\hline Greece & 0.1121 & 0.1144 & $-1.313 * * *$ & $0.7682 * *$ \\
\hline Spain & $-0.651 * * *$ & $-0.649 * * *$ & $0.4115 * *$ & 0.0053 \\
\hline Portugal & $-1.236 * * *$ & $-5.11 * * *$ & $-2.881 * * *$ & -0.423 \\
\hline Finland & $-5.526 * * *$ & $-5.525 * * *$ & $-5.368 * * *$ & $-5.116 * * *$ \\
\hline Sweden & $-4.808 * * *$ & $-4.993 * * *$ & $-5.78 * * *$ & $-4.623 * * *$ \\
\hline Austria & $-3.247 * * *$ & $-3.929 * * *$ & $-3.868 * * *$ & $-2.941 * * *$ \\
\hline \multirow{2}{*}{\multicolumn{5}{|c|}{ age (ref. age > 64) }} \\
\hline & & & & \\
\hline age $15-24$ & $0.2814 * * *$ & 0.0303 & $1.3226 * * *$ & 0.2181 \\
\hline age $25-34$ & $0.5104 * * *$ & -0.353 & $0.8929 * * *$ & $0.3515 *$ \\
\hline age $35-44$ & 0.0277 & -0.175 & $1.0121 * * *$ & -0.179 \\
\hline age $45-54$ & $0.4281 * * *$ & -0.061 & $0.6638 * * *$ & 0.1917 \\
\hline age $55-64$ & $0.5068 * * *$ & 0.1249 & $0.3994 * *$ & $0.3468 *$ \\
\hline household head & -0.042 & $0.4146 * * *$ & $0.3095 * *$ & 0.0909 \\
\hline married/parnered & $0.3017 * * *$ & 0.0825 & -0.029 & 0.0941 \\
\hline \multicolumn{5}{|l|}{ education (ref. stop education beforelat 15) } \\
\hline stop education between 16 and 19 & $0.6783 * * *$ & $0.2424 *$ & $-0.433 * * *$ & $0.4299 * * *$ \\
\hline stop education after 20 & $1.0654 * * *$ & $0.6507 * * *$ & 0.1269 & $0.5357 * * *$ \\
\hline \multicolumn{5}{|c|}{ labour market position (ref. high skilled white collars) } \\
\hline housekeeper & $-0.781 * * *$ & 0.2551 & $0.6139 * * *$ & -0.33 \\
\hline student & $-0.404 * * *$ & $0.5316 *$ & -0.378 & -0.473 \\
\hline unemployed & $-0.726 * * *$ & $0.693 * *$ & 0.1964 & -0.112 \\
\hline retired & $-0.448 * * *$ & $-0.579 * *$ & -0.012 & -0.075 \\
\hline farmer/fisherman & $-1.134 * * *$ & 0.2847 & $0.9686 *$ & -0.554 \\
\hline professional & $0.4256 * * *$ & 0.3325 & -0.493 & 0.4016 \\
\hline business proprietor & $-0.602 * * *$ & 0.2198 & 0.3554 & $-0.407 *$ \\
\hline low skill white-collar & $-0.413 * * *$ & 0.2949 & 0.0632 & -0.123 \\
\hline blue-collar & $-0.498 * * *$ & 0.2006 & 0.1673 & -0.017 \\
\hline \multicolumn{5}{|l|}{ political affiliation (ref. left) } \\
\hline political affiliation: right & $-1.206 * * *$ & $-0.896 * * *$ & $-0.715 * * *$ & $-0.959 * * *$ \\
\hline political affiliation: centre & $-0.222 * * *$ & -0.124 & -0.02 & -0.139 \\
\hline political affiliation: dk & $-1.07 * * *$ & $-0.926 * * *$ & $-0.348 * *$ & $-0.363 * *$ \\
\hline \multicolumn{5}{|l|}{ attitude twd membership (ref. bad) } \\
\hline attitude twd membership: good & $5.5393 * * *$ & $4.3056 * * *$ & $3.3997 * * *$ & $3.7803 * * *$ \\
\hline attitude twd membership: neutral & $3.173 * * *$ & $2.5261 * * *$ & $2.0352 * * *$ & $2.3167 * * *$ \\
\hline attitude twd membership: dk & $0.6517^{* * *}$ & $1.2847 * * *$ & $0.7906 * * *$ & 0.5829 ** \\
\hline \multicolumn{5}{|l|}{ country benefited from EU (ref. no) } \\
\hline thik own country benefited from EU: yes & $1.7842 * * *$ & $0.8263 * * *$ & $0.7573 * * *$ & $1.0114 * * *$ \\
\hline think own country benefited from EU: $\mathrm{dk}$ & $-0.187 * * *$ & -0.2 & 0.1096 & -0.17 \\
\hline \multicolumn{5}{|l|}{ year (ref. year 2003) } \\
\hline year 1999 & 0.1232 & & & \\
\hline year 2000 & -0.084 & & & \\
\hline year 2001 & 0.5675 & & & \\
\hline year 2002 & 0.0521 & & & \\
\hline EU knowledge & & $601 * * *$ & $0.1695 * * *$ & $0.1341^{* * *}$ \\
\hline
\end{tabular}


Table 6: Dependent variable EU56 (Europeanism on 26 domains)

\begin{tabular}{|c|c|c|c|c|}
\hline Variable & model $1^{\mathrm{a}}$ & model $2^{\mathrm{b}}$ & model $4^{\circ}$ & model $5^{\mathrm{d}}$ \\
\hline \multicolumn{5}{|l|}{ Country (ref. Italy) } \\
\hline France & $-1.878 * * *$ & $-2.162 * * *$ & $-2.309 * * *$ & $-0.994 * * *$ \\
\hline Belgium & $-1.886 * * *$ & $-1.713 * * *$ & $-2.651 * * *$ & $-1.279 * * *$ \\
\hline The Netherlands & $-3.208 * * *$ & $-3.554 * * *$ & $-4.001 * * *$ & $-2.026 * * *$ \\
\hline Germany & $-1.7 * * *$ & $-2.318 * * *$ & $-2.42 * * *$ & $-1.331 * * *$ \\
\hline Luxemburg & $-5.04 * * *$ & $-4.062 * * *$ & $-3.26 * *$ & $-4.608 * * *$ \\
\hline Denmark & $-5.495 * * *$ & $-6.228 * * *$ & $-6.523 * * *$ & $-4.928 * * *$ \\
\hline Ireland & $-3.482 * * *$ & $-4.609 * * *$ & $-3.594 * * *$ & $-2.368 * * *$ \\
\hline UK & $-3.94 * * *$ & $-3.805 * * *$ & $-3.742 * * *$ & $-2.634 * * *$ \\
\hline Greece & 0.0348 & 0.0727 & $-1.407 * * *$ & $0.7087^{* *}$ \\
\hline Spain & $-0.664 * * *$ & $-0.701 * * *$ & $0.3752 *$ & 0.0064 \\
\hline Portugal & $-1.326 * * *$ & $-5.253 * * *$ & $-3.015 * * *$ & -0.494 \\
\hline Finland & $-5.552 * * *$ & $-5.579 * * *$ & $-5.434 * * *$ & $-5.137 * * *$ \\
\hline Sweden & $-4.813 * * *$ & $-5.003 * * *$ & $-5.842 * * *$ & $-4.636 * * *$ \\
\hline Austria & $-3.357 * * *$ & $-3.987 * * *$ & $-3.959 * * *$ & $-3.042 * * *$ \\
\hline female & $-0.324 * * *$ & -0.104 & $-1 \mathrm{E}-03$ & -0.092 \\
\hline \multicolumn{5}{|l|}{ age (ref. age > 64) } \\
\hline age $15-24$ & $0.2795 * *$ & -0.008 & $1.3506 * * *$ & 0.2163 \\
\hline age $25-34$ & $0.5216 * * *$ & $-0.397 *$ & $0.9215 * * *$ & $0.3609 *$ \\
\hline age $35-44$ & 0.0287 & -0.206 & $1.0643 * * *$ & -0.185 \\
\hline age $45-54$ & $0.4364 * * *$ & -0.082 & $0.711 * * *$ & 0.1959 \\
\hline age $55-64$ & $0.5245 * * *$ & 0.1295 & $0.4229 * *$ & $0.3607 *$ \\
\hline household head & -0.049 & $0.4291 * * *$ & $0.3073 * *$ & 0.0922 \\
\hline married/parnered & $0.3256 * * *$ & 0.0838 & -0.044 & 0.1068 \\
\hline \multicolumn{5}{|l|}{ education (ref. stop education before/at 15) } \\
\hline stop education between 16 and 19 & $0.72 * * *$ & $0.2636 *$ & $-0.414 * * *$ & $0.464 * * *$ \\
\hline \multirow{2}{*}{\multicolumn{5}{|c|}{ labour market position (ref. high skilled white collars) }} \\
\hline & & & & \\
\hline housekeeper & $-0.83 * * *$ & 0.2501 & $0.6355 * * *$ & -0.359 \\
\hline student & $-0.355 * *$ & $0.5989 *$ & -0.344 & -0.421 \\
\hline unemployed & $-0.752 * * *$ & $0.6911 * *$ & 0.1861 & -0.106 \\
\hline retired & $-0.461 * * *$ & $-0.603 * *$ & -0.013 & -0.071 \\
\hline farmer/fisherman & $-1.163 * * *$ & 0.2954 & $0.9912 *$ & -0.567 \\
\hline professional & $0.458 * *$ & 0.3133 & -0.541 & 0.4339 \\
\hline business proprietor & $-0.605 * * *$ & 0.2316 & 0.3584 & -0.403 \\
\hline low skill white-collar & $-0.408 * * *$ & 0.3069 & 0.0655 & -0.108 \\
\hline \multirow{2}{*}{\multicolumn{5}{|c|}{ political affiliation (ref. left) }} \\
\hline & & & & \\
\hline political affiliation: right & $-1.24 * * *$ & $-0.918 * * *$ & $-0.713 * * *$ & $-0.984 * * *$ \\
\hline political affiliation: centre & $-0.219 * * *$ & -0.111 & -0.017 & -0.135 \\
\hline political affiliation: $\mathrm{dk}$ & $-1.127 * * *$ & $-0.964 * * *$ & $-0.355 * *$ & $-0.391 * *$ \\
\hline \multicolumn{5}{|l|}{ attitude twd membership (ref. bad) } \\
\hline attitude twd membership: good & $5.723 * * *$ & $4.4725 * * *$ & $3.5355 * * *$ & $3.891^{* * *}$ \\
\hline attitude twd membership: neutral & $3.3042 * * *$ & $2.6473 * * *$ & $2.1343 * * *$ & $2.4052 * * *$ \\
\hline attitude twd membership: dk & $0.6431 * * *$ & $1.2986 * * *$ & $0.7862 * * *$ & $0.5725 * *$ \\
\hline \multicolumn{5}{|l|}{ country benefited from EU (ref. no) } \\
\hline think own country benefited from EU: yes & $1.8315 * * *$ & $0.8405 * * *$ & $0.7724 * * *$ & $1.0357 * * *$ \\
\hline think own country benefited from EU: dk & $-0.199 * * *$ & -0.22 & 0.0956 & -0.181 \\
\hline \multicolumn{5}{|l|}{ year (ref. year 2003) } \\
\hline $\begin{array}{l}\text { year } 2001 \\
\text { year } 2002\end{array}$ & $\begin{array}{r}0.571 \\
0.0436\end{array}$ & & & \\
\hline \multirow{2}{*}{\multicolumn{5}{|c|}{$\begin{array}{l}\text { EU knowledge } \\
\text { feel more (ref. European) }\end{array}$}} \\
\hline & & & & \\
\hline feel more: own nationality & & $-0.887 * * *$ & $-1.41 * * *$ & $-1.347 * * *$ \\
\hline feel more: don't know & & $-1.974 * * *$ & $-1.911 * * *$ & $-1.074 * * *$ \\
\hline
\end{tabular}

\begin{tabular}{|c|c|c|c|c|}
\hline Variable & model $1^{\mathrm{a}}$ & $\operatorname{model} 2^{\mathrm{b}}$ & $\operatorname{model} 4^{\circ}$ & model $5^{\mathrm{d}}$ \\
\hline \multicolumn{5}{|l|}{ life satisfaction (ref. low) } \\
\hline life satisfaction: high & & -0.003 & $1.4176^{* * *}$ & $0.6493 * *$ \\
\hline life satisfaction: medium-high & & -0.224 & $1.502 * * *$ & $0.9276 * * *$ \\
\hline life satisfaction: medium-low & & -0.47 & $1.2485 * * *$ & $1.0684 * * *$ \\
\hline life satisfaction: $\mathrm{dk}$ & & $-1.992 * * *$ & -0.757 & -0.651 \\
\hline \multicolumn{5}{|l|}{ democracy satisfaction (own country) (ref.low) } \\
\hline democracy satisfaction (own country): high & & $-0.941 * * *$ & & $-0.834 * * *$ \\
\hline democracy satisfaction (own country): medium-high & & $-0.798 * * *$ & & $-0.576 * * *$ \\
\hline democracy satisfaction (own country): medium-low & & $-0.488 * *$ & & $-0.323 *$ \\
\hline democracy satisfaction (own country): dk & & $-1.563 * * *$ & & $-2.099 * * *$ \\
\hline \multicolumn{5}{|l|}{ democracy satisfaction (EU) (ref. low) } \\
\hline democracy satisfaction (EU): high & & $1.4477 * * *$ & & $1.9395 * * *$ \\
\hline democracy satisfaction (EU): medium-high & & $1.8721 * * *$ & & $2.3398 * * *$ \\
\hline democracy satisfaction (EU): medium-low & & $1.0571 * * *$ & & $1.347^{* * *}$ \\
\hline democracy satisfaction (EU): dk & & $0.7998 * * *$ & & $1.25 * * *$ \\
\hline tv frequency & & $0.3185 *$ & & \\
\hline newspaper frequency & & 0.0357 & & \\
\hline radio frequency & & 0.1485 & & \\
\hline \multicolumn{5}{|l|}{$\begin{array}{l}\text { income (ref. forth quartile) } \\
\text { incolo }\end{array}$} \\
\hline first income quartile & & $-0.521 * *$ & $-0.597 * * *$ & $-0.878 * * *$ \\
\hline second income quartile & & -0.106 & $-0.341 *$ & $-0.445 * *$ \\
\hline third income quartile & & $-0.353 *$ & -0.177 & -0.071 \\
\hline undeclared income & & $-0.566 * * *$ & $-0.699 * * *$ & $-0.86 * * *$ \\
\hline \multicolumn{5}{|l|}{ area of living (ref. rural) } \\
\hline area of living: large town & & 0.1374 & -0.188 & -0.079 \\
\hline area of living: small town & & $0.2346 *$ & $-0.292 * *$ & -0.146 \\
\hline area of living: $\mathrm{dk}$ & & -0.896 & -0.206 & 0.7007 \\
\hline \multicolumn{5}{|l|}{ proud to be of own nationality (ref. low) } \\
\hline proud to be of own nationality: high & & $-2.392 * * *$ & $-3.38 * * *$ & $-2.722 * * *$ \\
\hline proud to be of own nationality: medium-high & & $-1.883 * * *$ & $-2.337 * * *$ & $-2.414 * * *$ \\
\hline proud to be of own nationality: medium-low & & $-1.539 * * *$ & $-1.073 * * *$ & $-1.576 * * *$ \\
\hline proud to be of own nationality: $\mathrm{dk}$ & & $-1.355 * * *$ & $-2.272 * * *$ & $-1.822 * * *$ \\
\hline \multicolumn{5}{|l|}{ proud to be European (ref. low) } \\
\hline proud to be European: high & & $3.7052 * * *$ & $4.0785 * * *$ & $3.6779 * * *$ \\
\hline proud to be European: medium-high & & $3.2179 * * *$ & $3.1759 * * *$ & $3.2969 * * *$ \\
\hline proud to be European: medium-low & & $2.1728 * * *$ & $1.7931 * * *$ & $1.41 * * *$ \\
\hline proud to be European: $\mathrm{dk}$ & & $2.1021 * * *$ & $1.9604 * * *$ & $1.3756 * * *$ \\
\hline \\
\hline personal advantage from membership: high & & & $2.0951 * * *$ & \\
\hline personal advantage from membership: medium & & & $1.3907 * * *$ & \\
\hline personal advantage from membership: $\mathrm{dk}$ & & & $0.4524 * *$ & \\
\hline probability to vote (national election) & & & -0.021 & $-0.066 * * *$ \\
\hline $\begin{array}{l}\text { probability to vote (European election) } \\
\text { Constant }\end{array}$ & $11367 * * *$ & $12212 * * *$ & $\begin{aligned} 0.201 * * * * \\
1008 * * *\end{aligned}$ & $0.2354^{* * *}$ \\
\hline Number of obs & 80402 & 15939 & 16012 & $\frac{10.100}{16070}$ \\
\hline Prob $>$ F & 0.000 & 0.000 & 0.000 & 0.000 \\
\hline R-squared & 0.240 & 0.233 & 0.295 & 0.294 \\
\hline
\end{tabular}

a: estimated on all surveys after 54 ; b: estimated on survey 56 ; c: estimated on survey 57 ; d: estimated on survey 60 . 
Table 7: Dependent variable EU57 (Europeanism on 27 domains)

\begin{tabular}{|c|c|c|c|}
\hline Variable & model $1^{\mathrm{a}}$ & $\operatorname{model} 4^{\mathrm{b}}$ & $\operatorname{model} 5^{\mathrm{c}}$ \\
\hline \multicolumn{4}{|l|}{ Country (ref. Italy) } \\
\hline France & $-1.982 * * *$ & $-2.385 * * *$ & $-1.071 * * *$ \\
\hline Belgium & $-2.016 * * *$ & $-2.777 * * *$ & $-1.385 * * *$ \\
\hline The Netherlands & $-3.584 * * *$ & $-4.392 * * *$ & $-2.354 * * *$ \\
\hline Germany & $-1.876 * * *$ & $-2.536 * * *$ & $-1.491 * * *$ \\
\hline Luxemburg & $-5.284 * * *$ & $-3.426 * *$ & $-4.834 * * *$ \\
\hline Denmark & $-5.928 * * *$ & $-6.96 * * *$ & $-5.341 * * *$ \\
\hline Ireland & $-3.61 * * *$ & $-3.649 * * *$ & $-2.464 * * *$ \\
\hline UK & $-4.118 * * *$ & $-3.851 * * *$ & $-2.756 * * *$ \\
\hline Greece & 0.0289 & $-1.356 * * *$ & $0.7149 * *$ \\
\hline Spain & $-0.732 * * *$ & $0.4588 * *$ & -0.037 \\
\hline Portugal & $-1.382 * * *$ & $-3.082 * * *$ & -0.528 \\
\hline Finland & $-5.924 * * *$ & $-5.724 * * *$ & $-5.49 * * *$ \\
\hline Sweden & $-5.17 * * *$ & $-6.163 * * *$ & $-4.982 * * *$ \\
\hline Austria & $-3.461 * * *$ & $-4.006 * * *$ & $-3.136 * * *$ \\
\hline female & $-0.341 * * *$ & 0.0007 & -0.1 \\
\hline \multicolumn{4}{|l|}{ age (ref. age > 64) } \\
\hline age $15-24$ & $0.2563 *$ & $1.4555 * * *$ & 0.1888 \\
\hline age 25-34 & $0.5308 * * *$ & $1.0003 * * *$ & 0.3624 \\
\hline age $35-44$ & 0.0283 & $1.1453 * * *$ & -0.193 \\
\hline age 45-54 & $0.4607 * * *$ & $0.786 * * *$ & 0.2117 \\
\hline age 55-64 & $0.5578 * * *$ & $0.4683 * *$ & $0.3887 * *$ \\
\hline household head & -0.052 & $0.3408 * *$ & 0.0829 \\
\hline married/parnered & $0.3306 * * *$ & -0.054 & 0.1093 \\
\hline \multicolumn{4}{|l|}{ education (ref. stop education before/at 15) } \\
\hline stop education between 16 and 19 & $0.7447 * * *$ & $-0.412 * * *$ & $0.4801 * * *$ \\
\hline stop education after 20 & $1.1638 * * *$ & 0.1746 & $0.6017 * * *$ \\
\hline \multicolumn{4}{|c|}{ labour market position (ref. high skilled white collars) } \\
\hline housekeeper & $-0.863 * * *$ & $0.6437 * *$ & -0.388 \\
\hline student & $-0.383 * *$ & -0.336 & -0.453 \\
\hline unemployed & $-0.792 * * *$ & 0.1888 & $\begin{array}{l}-0.433 \\
-0.138\end{array}$ \\
\hline retired & $-0.498 * * *$ & 0.023 & -0.102 \\
\hline farmer/fisherman & $-1.184 * * *$ & 1.0171 * & -0.569 \\
\hline professional & $0.4867 * *$ & -0.603 & 0.4673 \\
\hline business proprietor & $-0.615 * * *$ & 0.3842 & -0.404 \\
\hline low skill white-collar & $-0.419 * * *$ & 0.088 & -0.112 \\
\hline blue-collar & $-0.51 * * *$ & 0.1914 & 0.0012 \\
\hline \multicolumn{4}{|l|}{ political affiliation (ref. left) } \\
\hline political affiliation: right & $-1.31 * * *$ & $-0.732 * * *$ & $-1.045 * * *$ \\
\hline political affiliation: centre & $-0.222 * * *$ & -0.011 & -0.134 \\
\hline political affiliation: $\mathrm{dk}$ & $-1.169 * * *$ & $-0.344 * *$ & $-0.405 * *$ \\
\hline \multicolumn{4}{|l|}{ attitude twd membership (ref. bad) } \\
\hline attitude twd membership: good & $5.9139 * * *$ & $3.6819 * * *$ & $4.022 * * *$ \\
\hline attitude twd membership: neutral & $3.4129 * * *$ & $2.2194 * * *$ & $2.4873 * * *$ \\
\hline \multirow{2}{*}{\multicolumn{4}{|c|}{$\begin{array}{l}\text { attunde twd memebership: a } \\
\text { country benefited from } E U \text { (ref. no) }\end{array}$}} \\
\hline & & & \\
\hline think own country benefited from EU: yes & $1.9044 * * *$ & $0.8016 * * *$ & $1.0778 * * *$ \\
\hline think own country benefited from EU: $\mathrm{dk}$ & $-0.209 * *$ & 0.0961 & -0.187 \\
\hline \multicolumn{4}{|l|}{$\begin{array}{l}\text { year (ref, year 2003) } \\
\text { vear } 2002\end{array}$} \\
\hline & 0.0661 & & \\
\hline \multirow{2}{*}{\multicolumn{4}{|c|}{$\begin{array}{l}\text { EU knowelege } \\
\text { feel more (ref. European) }\end{array}$}} \\
\hline & & & \\
\hline feel more: own nationality & & $-1.463 * * *$ & $-1.383 *$ \\
\hline feel more: don't know & & $-1.938 * * *$ & $-1.12 * * *$ \\
\hline
\end{tabular}

\begin{tabular}{|c|c|c|c|}
\hline Variable & model $1^{\mathrm{a}}$ & $\operatorname{model} 4^{\mathrm{b}}$ & model $5^{\mathrm{c}}$ \\
\hline \multicolumn{4}{|l|}{ life satisfaction (ref. low) } \\
\hline life satisfaction: high & & $1.461 * * *$ & $0.6344 * *$ \\
\hline life satisfaction: medium-high & & $1.5721 * * *$ & $0.9319 * * *$ \\
\hline life satisfaction: medium-low & & $1.3054 * * *$ & $1.0952 * * *$ \\
\hline life satisfaction: $\mathrm{dk}$ & & -0.768 & -0.669 \\
\hline \multicolumn{4}{|l|}{ democracy satisfaction (own country) (ref. low) } \\
\hline democracy satisfaction (own country): high & & & $-0.842 * * *$ \\
\hline democracy satisfaction (own country): medium-high & & & $-0.595 * * *$ \\
\hline democracy satisfaction (own country): medium-low & & & -0.317 \\
\hline democracy satisfaction (own country): dk & & & $-2.154 * * *$ \\
\hline \multicolumn{4}{|l|}{ democracy satisfaction (EU) (ref. low) } \\
\hline democracy satisfaction (EU): high & & & $2.002 * * *$ \\
\hline democracy satisfaction (EU): medium-high & & & $2.3859 * * *$ \\
\hline democracy satisfaction (EU): medium-low & & & $1.3202 * * *$ \\
\hline democracy satisfaction (EU): dk & & & 1.2175 *** \\
\hline \multirow{2}{*}{\multicolumn{4}{|c|}{$\begin{array}{l}\text { tv frequency } \\
\text { newspnaner freapency }\end{array}$}} \\
\hline \multirow{2}{*}{\multicolumn{4}{|c|}{$\begin{array}{l}\text { newspaper frequency } \\
\text { radio frequency }\end{array}$}} \\
\hline & & & \\
\hline \multicolumn{4}{|l|}{ income (ref. forth quartile) } \\
\hline first income quartile & & $-0.627 * * *$ & $-0.871 * * *$ \\
\hline second income quartile & & $-0.336 *$ & $-0.444 * *$ \\
\hline third income quartile & & -0.176 & -0.061 \\
\hline undeclared income & & $-0.717 * * *$ & $-0.896 * * *$ \\
\hline \multicolumn{4}{|l|}{ area of living (ref. rural) } \\
\hline area of living: large town & & -0.18 & -0.067 \\
\hline area of living: small town & & $-0.298 * *$ & -0.15 \\
\hline area of living: $\mathrm{dk}$ & & -0.304 & 0.7658 \\
\hline \multicolumn{4}{|l|}{ proud to be of own nationality (ref. low) } \\
\hline proud to be of own nationality: high & & $-3.516 * * *$ & $-2.816^{* * *}$ \\
\hline proud to be of own nationality: medium-high & & $-2.434 * * *$ & $-2.509 * * *$ \\
\hline proud to be of own nationality: medium-low & & $-1.139 * * *$ & $-1.653^{* * *}$ \\
\hline proud to be of own nationality: dk & & $-2.375 * * *$ & $-1.925 * * *$ \\
\hline \multicolumn{4}{|l|}{ proud to be European (ref. low) } \\
\hline proud to be European: high & & $4.2441 * * *$ & $3.824 * * *$ \\
\hline proud to be European: medium-high & & $3.3264 * * *$ & $3.4321 * * *$ \\
\hline proud to be European: medium-low & & $1.8964 * * *$ & $1.4678^{* * *}$ \\
\hline \multirow{2}{*}{\multicolumn{4}{|c|}{$\begin{array}{l}\text { proud to be European: dk } \\
\text { personal advantage from membership (ref. low) }\end{array}$}} \\
\hline & & & \\
\hline personal advantage from membership: high & & $2.1595 * * *$ & \\
\hline personal advantage from membership: medium & & $1.4312 * * *$ & \\
\hline personal advantage from membership: $\mathrm{dk}$ & & $0.453 * *$ & \\
\hline probability to vote (national election) & & -0.02 & $-0.072 * * *$ \\
\hline probability to vote (European election) & & $0.2085 * * *$ & $0.2465 * * *$ \\
\hline Constant & $11.849 * * *$ & $10.318 * * *$ & $10.654 * * *$ \\
\hline Number of obs & & 16012 & \\
\hline Prob $>\mathrm{F}$ & 0.000 & 0.000 & 0.000 \\
\hline R-squared & 0.239 & 0.296 & 0.293 \\
\hline
\end{tabular}

a: estimated on all surveys after 57 ; b: estimated on survey 57 ; c: estimated on survey 60 . 
In particular, Belgium results less pro-European than France, Germany and Portugal in models with EU52, EU56 and EU57 as dependent variables, Spain, Greece and Italy confirm in all models and with all considered dependent variables as the more pro-EU countries.

One potential explanation may be the weakness of national government institutions in these countries. This hypothesis is supported by graph 3, where we have depicted country coefficients as emerged from estimation of Europeanism equation on 2003 data (survey 60) using UE43 as dependent variable (however, results are similar using the other dependent variables) and the average value of the 2003 governance indicators provided by the World Bank ${ }^{1}$. A clear negative relationship can be noticed; hence, citizens seem to prefer EU competence when they do not trust much their own country institutions.

\section{Graph 3: Europeanism and mean governance indicator}

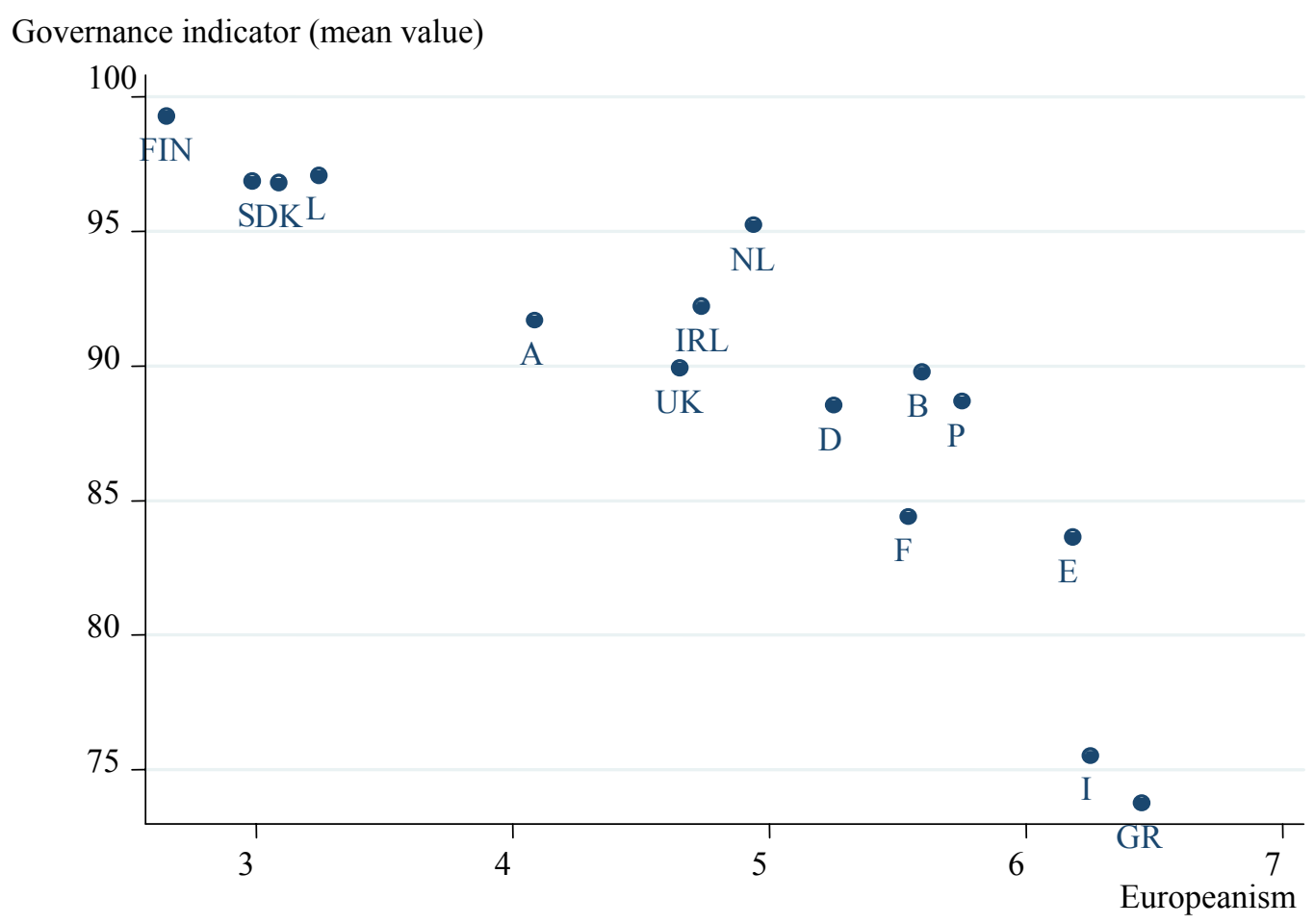

When using EU43 as dependent variable, in model 1 female citizens appear less Europeanist than men, although when controlling for a wider range of variables the female coefficient is negative but no more statistically significant. This is true also when considering the other four dependent variables. As for the impact of age, no clear trend emerges, although, recalling that the excluded category is older than 65 citizens, the positive and significant coefficient of the other age ranges dummy variables in almost all models and with almost all dependent variables suggests that older citizens tend to be less Europeanist than younger ones. Notice also that when controlling for the 
level of democracy satisfaction in own country and in Europe the age coefficients are no more statistically significant.

Married/partnered individuals seem to be more pro-European on the basis of results based on model 1 estimation (whatever the dependent variable), but this results is not robust to the change in the equation specification, as the coefficient is no more significant in the less parsimonious models.

Interestingly, as the education level grows, so does the Europeanism degree: citizens who stopped full time education between 15 and 19 years old want to delegate a larger number of policy issue to Europe with respect to citizens who stopped full time education earlier than 15 years old, and citizens who finished studying after 20 years old are the most pro-European among UE citizens ${ }^{2}$. Considering individuals' labour market position, in model 1 (the most parsimonious) high-skilled white collars (the excluded category) result more pro-European than all other UE citizens (with exception of self employed professionals) whatever the dependent variable; nonetheless, when controlling for wider sets of variables, no more labour market position effect emerges from estimation.

A quite interesting and robust result regards the link between political membership and the degree of Europeanism: independently of the model and of the dependent variable considered, left-side citizens are more in favour of allocation of competences to Europe than both right-side citizens and citizens who don't have a political position. The negative sign of the centre-membership dummy variable coefficient points to a smaller degree of Europeanism of centre citizens with respect to leftside citizens; however, the coefficient is practically always non significant.

With regard to the impact of income, being the excluded category the highest income quartile, estimation results suggest a positive relation between household income and Europeanism. However, these results are not particularly reliable as around one third of the respondents do not declare his/her own household income ${ }^{3}$.

Turning to the association between Europeanism and attitude towards EU, the results are in line with expectations. We measure attitude towards UE trough a number of different variables. The first variable relates to whether the respondent thinks his/her country's membership is good, bad, neither good nor bad or don't know. As expected, citizens who think that membership is good are more in favour of delegation of competencies to EU than citizens who think membership is neither good nor

\footnotetext{
${ }^{1}$ Kaufmann et al. (2005). The six indicators are: voice and accountability, political stability/no violence, government effectiveness, regulatory quality, rule of law and control of corruption.

${ }^{2}$ Only in model 4 (estimated on Eurobarometer 57), which controls for personal advantages the respondent thinks has received from his/her country EU membership, this is not confirmed. Indeed, we have verified that there is a positive correlation between this latter variable and education, thus its inclusion takes away statistical significance to the education variables.

${ }^{3}$ Since dropping observations with missing values on income would have caused a sample reduction of around one third, we have preferred to keep these observations and to build a dummy variable in order to distinguish them from observations without missing values on income.
} 
bad who, in turn, are more in favour of EU competence than citizens who think own country's membership is bad. Citizens who are not able to express an opinion with regard to this issue are more pro-European than those who think membership is bad. Unsurprisingly, individuals who think that, taking everything into consideration, their country has on balance benefited from membership want to delegate a larger number of policy domains to EU. The same is true for citizens who feel more European than of their own nationality. In models 2, 4 and 5 there are two groups of variables describing how UE citizens are proud to be of their own nationality and to be European. As expected, with the increase in the degree of the pride to be European, also the preference for EU involvement raises. On the contrary, results show a negative relation between the pride to be of own nationality and Europeanism. Finally, if the respondent thinks he/she has received personal advantages from his/her country's EU membership, his/her preference for EU competence increases.

Another group of variables proxies the degree of information and of public spirit of UE citizens. The first relates to how much the respondent thinks he/she is informed about EU, its policies and its institutions (on a 1-10 scale). Interestingly, in all models and specifications a positive relation between this variable and the number of policy domains that citizens want to delegate to EU emerges; the other variables refer to the frequency by which the respondents watch the news on television, read the news in daily papers and listen to the news on the radio. The positive coefficients' signs point to a positive effect of these variables on Europeanism, but only in model 3 we find statistical significance. Finally, two variables measure the probability to vote (on a 1-10 scale) in national and UE elections, which can be taken as measures of public spirit. Despite the positive correlation between these two variables (Pearson correlation coefficient equal to 0.72), their impact on the degree of Europeanism is opposite: a positive and significant coefficient of the variable measuring the probability to vote in EU elections suggests that this variable is positively correlated with the number of policy domains that citizens would like to assign to Europe, while the negative sign of the coefficient of the variable measuring the probability to vote in national elections point to a negative impact of this variable on Europeanism ${ }^{4}$.

Finally, turning to other personal controls, results from the less parsimonious models 4 and 5 show that, with respect to people that are not at all satisfied with the life they lead, other UE citizens result more pro-Europeanist. Estimation results do not point out any clear pattern with regard to the influence of the type of area of living (depending on the model and on the adopted specification coefficients change in size, sign, and statistical significance). Finally, religious affiliation is not related to preferences for competences' assignment. 


\subsection{Only Europeanism or awareness? What drives preferences for allocation of competences?}

In the previous section we have considered factors determining a generic degree of Europeanism or preference for centralisation. As a second step of our econometric analysis, we select a certain number of the policy domains previously considered and, for each of them, we try to investigate which individual characteristics make European citizens more prone to prefer centralisation of competences. In other words, given that we consider separately public goods or policy domains, we intend to gain more insights on specific individual characteristics which may explain heterogeneity of preferences for competence allocation for single policy areas. To this aim, we estimate different probit models, one for each policy domain, using as dependent variables the $0 / 1$ dichotomous variables taking value 1 for citizens stating that their preferred allocation of competence is to EU and 0 otherwise.

The domains we consider are defence, foreign policy, environment, poverty and social exclusion, agriculture, research, unemployment, regional aid, education, immigration and terrorism. We estimate the probit models on survey 56.2 (which refers to 2001) since it contains the largest number of explanatory variables whose effect we are interested to study. In addition, taking into account estimation results described in the previous section, we include the dependent variable of the previous estimates among the regressors computed excluding the domain under study. This variable is a measure of the level of Europeanism of citizens, since it measures the number of domains the individuals want to delegate to EU. Thus, the higher the value of this variable, the higher the preference for centralisation.

The reason for introducing this variable is that some people may be wishing to allocate competence to Europe or to their country not for an economic (efficiency) reason, but because they are in general in favour or contrary to Europe. Indeed, in the previous section we have verified that some personal characteristics are related to the number of domains European citizens want to delegate to EU. Thus, we want to evaluate the factors driving people's preferences after controlling for their degree of Europeanism. Estimation results are shown in Table 8.

The first thing to be noticed is that, as expected, the higher the level of Europeanism, the higher the probability of preference for centralisation, whatever the considered domain. However, even after controlling for this variable, depending on the area considered there are other personal characteristics that influence preference for centralisation in a statistically significant way.

In the last section we identified a ranking among countries according to their level of Europeanism. Nonetheless, considering preference for allocation separately for policy domain, some important distinction should be made.

\footnotetext{
${ }^{4}$ This is the result from model 4; however, in model 5 this variable is no more statistically significant.
} 
Table 8: Preference for centralisation by issue

\begin{tabular}{|c|c|c|c|c|c|c|c|c|c|c|c|}
\hline Variable & defense & foreign policy & environment & $\begin{array}{l}\text { poverty/social } \\
\text { exclusion }\end{array}$ & agricolture & research & unemployment & regional aid & education & immigration & terrorism \\
\hline France & $-0.065 * * *$ & 0.008 & $0.072 * * *$ & 0.014 & $0.070 * * *$ & 0.017 & $-0.062 * * *$ & $-0.024 * *$ & $-0.070 * * *$ & $-0.050 * * *$ & $0.036^{* * *}$ \\
\hline Belgium & 0.021 & $0.052 * * *$ & 0.006 & $-0.032 *$ & $0.171 * * *$ & 0.000 & $-0.092 * * *$ & $0.130 * * *$ & $-0.163 * * *$ & -0.020 & $0.049 * * *$ \\
\hline The Netherlands & $0.050 * * *$ & 0.006 & $0.080 * * *$ & $-0.099 * * *$ & $0.105 * * *$ & $-0.053 * * *$ & $-0.161 * * *$ & $0.067 * * *$ & $-0.136 * * *$ & 0.014 & $0.022 *$ \\
\hline Germany & 0.008 & $0.039 * * *$ & $0.101 * * *$ & $0.042 * * *$ & $0.149 * * *$ & $-0.106 * * *$ & $-0.036^{* * *}$ & $0.107^{* * *}$ & $-0.072 * * *$ & $-0.177^{* * *}$ & $0.025 * * *$ \\
\hline Luxemburg & 0.020 & 0.069 & 0.042 & -0.015 & 0.069 & 0.120 & $-0.160 *$ & 0.134 & -0.139 & -0.145 & 0.059 \\
\hline Denmark & -0.019 & -0.027 & $0.058 * *$ & $0.073 * * *$ & $0.213 * * *$ & $0.045 *$ & $-0.098 * * *$ & $0.216 * * *$ & -0.025 & $-0.148 * * *$ & $0.099 * * *$ \\
\hline Ireland & $-0.201 * * *$ & -0.025 & -0.021 & 0.034 & $0.077 * *$ & 0.046 & -0.030 & $0.196 * * *$ & -0.016 & $-0.170 * * *$ & 0.040 \\
\hline UK & -0.021 & $-0.038 * * *$ & $0.081 * * *$ & $0.076 * * *$ & $0.103 * * *$ & 0.000 & $-0.063 * * *$ & $0.160 * * *$ & $-0.065 * * *$ & $-0.129 * * *$ & $0.053 * * *$ \\
\hline Greece & $-0.152 * * *$ & $-0.082 * * *$ & 0.020 & -0.029 & 0.004 & -0.016 & -0.016 & $0.068 * * *$ & 0.033 & -0.026 & $-0.043 * * *$ \\
\hline Spain & $-0.042 * * *$ & -0.017 & $0.047 * * *$ & 0.010 & $0.081 * * *$ & $-0.038 * * *$ & $-0.090 * * *$ & $0.085 * * *$ & $-0.060 * * *$ & 0.002 & $-0.032 * * *$ \\
\hline Portugal & $-0.115 * * *$ & -0.013 & 0.008 & 0.031 & $0.081 * * *$ & -0.025 & -0.011 & $0.147^{* * *}$ & $-0.041 * *$ & $-0.080 * * *$ & 0.006 \\
\hline Finland & $-0.306 * * *$ & $0.047 *$ & -0.034 & 0.019 & -0.025 & -0.030 & $-0.085 * * *$ & $0.183^{* * *}$ & $-0.047 *$ & $-0.274 * * *$ & $0.103 * * *$ \\
\hline Sweden & $-0.227 * * *$ & 0.001 & $0.052 * *$ & $0.106 * * *$ & $0.122 * * *$ & -0.020 & 0.027 & $0.179 * * *$ & 0.014 & $-0.146 * * *$ & $0.131 * * *$ \\
\hline Austria & $-0.087 * * *$ & 0.008 & -0.011 & $0.050 * *$ & -0.006 & -0.005 & 0.029 & $0.131 * * *$ & -0.027 & $-0.212 * * *$ & $0.055 * * *$ \\
\hline female & -0.007 & -0.008 & -0.005 & -0.007 & -0.003 & $0.016 * *$ & $0.015^{* *}$ & $-0.018 * *$ & $0.014 * *$ & $0.023 * * *$ & 0.000 \\
\hline age & 0.002 & $-0.002 *$ & 0.002 & $-0.002 *$ & $0.003 * *$ & 0.001 & 0.000 & $-0.002 *$ & 0.000 & -0.001 & 0.001 \\
\hline squared age & 0.000 & 0.000 & 0.000 & 0.000 & $0.000 * *$ & 0.000 & 0.000 & 0.000 & 0.000 & 0.000 & 0.000 \\
\hline household head & -0.014 & 0.007 & $0.037 * * *$ & -0.008 & $0.030 * * *$ & $0.015 * *$ & 0.011 & $0.014 *$ & 0.004 & $-0.018 * *$ & 0.002 \\
\hline married/parnered & $-0.015 *$ & $0.013 *$ & 0.003 & 0.005 & -0.005 & -0.002 & $0.014 *$ & $0.019^{* *}$ & 0.006 & -0.008 & -0.002 \\
\hline education: medium & 0.004 & -0.001 & 0.001 & $-0.020 * * *$ & $-0.016 *$ & $0.034 * * *$ & -0.003 & 0.009 & $-0.028 * * *$ & 0.010 & $0.013 * *$ \\
\hline education: high & -0.012 & $-0.032 * * *$ & $0.027 * * *$ & $-0.020 * *$ & -0.006 & -0.005 & 0.000 & -0.002 & $-0.018 *$ & $0.033 * * *$ & 0.003 \\
\hline housekeeper & $-0.030 * *$ & $0.031 * *$ & 0.013 & 0.013 & 0.011 & -0.014 & 0.022 & -0.001 & 0.013 & -0.016 & -0.011 \\
\hline student & -0.027 & $-0.033 *$ & $0.053 * * *$ & 0.003 & $-0.074 * * *$ & 0.002 & 0.024 & -0.009 & 0.008 & -0.003 & $0.054 * * *$ \\
\hline unemployed & -0.022 & $0.051 * * *$ & 0.008 & 0.022 & -0.014 & 0.021 & 0.019 & -0.015 & 0.011 & -0.013 & -0.020 \\
\hline retired & $-0.043 * * *$ & $0.026 *$ & -0.006 & 0.011 & -0.020 & $-0.024 *$ & $0.033 * *$ & 0.001 & 0.019 & -0.016 & -0.002 \\
\hline farmer/fisherman & 0.009 & -0.022 & 0.006 & $0.054 *$ & $-0.173 * * *$ & -0.008 & $0.066^{* *}$ & -0.028 & $-0.070 * *$ & -0.001 & 0.004 \\
\hline professional & $-0.053 * *$ & 0.013 & -0.036 & 0.021 & -0.001 & 0.021 & 0.016 & -0.042 & 0.021 & -0.001 & -0.028 \\
\hline business proprietor & -0.015 & 0.022 & 0.002 & 0.015 & $-0.034 * *$ & $-0.037 * *$ & 0.018 & -0.007 & 0.021 & -0.002 & 0.005 \\
\hline low skill white-collar & $-0.026 * *$ & $0.028 * *$ & $0.022 *$ & 0.009 & $-0.022 *$ & 0.006 & 0.002 & -0.020 & 0.010 & -0.008 & 0.003 \\
\hline blue-collar & $-0.049 * * *$ & 0.008 & 0.001 & -0.013 & $-0.044 * * *$ & $-0.022 *$ & 0.020 & $-0.032 * *$ & $0.031 * *$ & -0.008 & 0.009 \\
\hline political affiliation: right & 0.003 & 0.014 & 0.009 & $-0.021 * *$ & $-0.017 *$ & 0.005 & -0.008 & 0.005 & $0.025 * * *$ & $-0.029 * * *$ & 0.005 \\
\hline political affiliation: centre & $0.015 *$ & -0.001 & 0.000 & 0.008 & $-0.022 * * *$ & -0.001 & 0.004 & 0.008 & $0.015 *$ & -0.007 & $0.016^{* * *}$ \\
\hline political affiliation: $\mathrm{dk}$ & 0.000 & $-0.023 * * *$ & -0.007 & $-0.027 * * *$ & 0.008 & $-0.019 * *$ & -0.007 & $-0.020 * *$ & $0.029 * * *$ & 0.011 & -0.011 \\
\hline attitude twd membership: good & $0.038 * * *$ & $0.029 * *$ & $0.037 * * *$ & $0.071 * * *$ & $0.050 * * *$ & $-0.026 * *$ & -0.006 & $0.032 * *$ & $-0.064 * * *$ & -0.005 & $0.040 * * *$ \\
\hline attitude twd membership: neutral & 0.000 & $0.031 * * *$ & $0.030 * * *$ & $0.060 * * *$ & $0.026 * *$ & -0.004 & -0.013 & $0.020 *$ & $-0.046 * * *$ & $-0.020 *$ & $0.046 * * *$ \\
\hline attitude twd membership: dk & -0.004 & -0.011 & 0.008 & $0.038 * *$ & $0.037^{* *}$ & $-0.055 * * *$ & 0.023 & -0.003 & 0.005 & $0.030 *$ & $-0.023 *$ \\
\hline think country benef. from EU: yes & 0.006 & 0.000 & 0.012 & $-0.016 *$ & 0.015 & 0.000 & $0.017 *$ & -0.003 & 0.003 & -0.003 & -0.010 \\
\hline think country benef. from EU: $\mathrm{dk}$ & -0.009 & $-0.018 *$ & -0.001 & $-0.017 *$ & -0.001 & 0.002 & $-0.016 *$ & $-0.030 * * *$ & 0.013 & 0.000 & $-0.015 * *$ \\
\hline EU knowledge & 0.002 & 0.001 & $0.006 * * *$ & 0.001 & $0.004 * *$ & -0.001 & 0.001 & 0.001 & $-0.004 * *$ & 0.000 & $0.004 * * *$ \\
\hline
\end{tabular}


Table 8: Preferences for centralisationby issue (continued)

\begin{tabular}{|c|c|c|c|c|c|c|c|c|c|c|c|}
\hline Variable & defense & foreign policy & environment & $\begin{array}{c}\text { poverty/social } \\
\text { exclusion }\end{array}$ & agricolture & research & unemployment & regional aid & education & immigration & terrorism \\
\hline feel more: own nationality & $-0.030 * * *$ & $0.029 * * *$ & $0.018 *$ & 0.013 & -0.010 & $0.020 * *$ & -0.013 & -0.001 & $-0.052 * * *$ & -0.003 & $0.028 * * *$ \\
\hline feel more: $\mathrm{dk}$ & $-0.041 *$ & 0.000 & $-0.035 *$ & -0.024 & $-0.055 * *$ & 0.008 & 0.010 & -0.022 & $-0.039 *$ & -0.002 & $-0.035 * *$ \\
\hline life satisfaction: high & 0.030 & -0.003 & $0.056 * * *$ & 0.027 & -0.020 & 0.028 & $-0.042 * *$ & -0.012 & $-0.043 * *$ & $0.058 * * *$ & $0.030 * *$ \\
\hline life satisfaction: medium-high & 0.021 & -0.013 & $0.052 * * *$ & 0.021 & -0.001 & 0.007 & $-0.040 * *$ & $-0.044 * *$ & $-0.039 * *$ & $0.040 * *$ & 0.021 \\
\hline life satisfaction: medium-low & 0.027 & -0.015 & $0.048 * *$ & 0.024 & 0.002 & -0.021 & -0.015 & $-0.041 * *$ & -0.017 & 0.013 & 0.008 \\
\hline life satisfaction: $\mathrm{dk}$ & 0.035 & -0.055 & 0.059 & 0.008 & -0.001 & -0.021 & $0.091 * *$ & -0.054 & -0.058 & 0.041 & -0.036 \\
\hline demo sat. (own country): high & $-0.049 * * *$ & 0.001 & -0.023 & 0.002 & -0.001 & -0.004 & $0.037^{* *}$ & $0.043 * *$ & $0.040^{* *}$ & -0.020 & 0.016 \\
\hline demo sat. (own country): medium-high & -0.009 & $0.034 * *$ & -0.012 & $0.026^{* *}$ & -0.018 & $0.024 *$ & 0.022 & $0.033 * *$ & 0.019 & -0.014 & $0.037 * * *$ \\
\hline demo sat. (own country): medium-low & -0.002 & $0.037 * * *$ & 0.008 & $0.025 * *$ & -0.012 & $0.025 * *$ & $0.027 * *$ & 0.019 & $0.022 *$ & -0.019 & $0.027 * * *$ \\
\hline demo sat. (own country): dk & -0.013 & -0.009 & -0.026 & 0.027 & 0.010 & $0.041 * *$ & 0.026 & 0.020 & $0.049^{* *}$ & $0.048 * *$ & $-0.046 * * *$ \\
\hline demo sat. (EU): high & 0.034 & $0.035 *$ & 0.013 & $-0.036 *$ & $0.050 * *$ & -0.003 & $-0.050 * *$ & -0.008 & $0.036 *$ & $-0.048 * *$ & $-0.040 * *$ \\
\hline demo sat. (EU): medium-high & 0.011 & $0.044 * * *$ & 0.006 & $-0.042 * * *$ & $0.043 * * *$ & 0.005 & $-0.052 * * *$ & 0.004 & 0.008 & $-0.037 * *$ & $-0.021 * *$ \\
\hline demo sat. (EU): medium-low & -0.003 & 0.016 & -0.010 & -0.019 & $0.028 * *$ & 0.006 & $-0.032 * *$ & $0.030 * *$ & -0.008 & $-0.030 * *$ & -0.010 \\
\hline demo sat. (EU): dk & 0.001 & $0.036 * * *$ & $-0.025 *$ & $-0.028 * *$ & 0.002 & 0.010 & $-0.029 * *$ & -0.006 & -0.005 & -0.020 & 0.012 \\
\hline tv frequency & $-0.022 * *$ & 0.015 & 0.014 & 0.007 & $0.025 * *$ & $0.034 * * *$ & $-0.020 * *$ & $0.029 * * *$ & $-0.047 * * *$ & $-0.037 * * *$ & $0.033 * * *$ \\
\hline newspaper frequency & $0.020 * * *$ & 0.007 & 0.002 & $0.011 *$ & -0.005 & -0.008 & $0.014 * *$ & $-0.017 * *$ & 0.006 & 0.011 & $-0.010 *$ \\
\hline radio frequency & -0.002 & -0.006 & -0.002 & -0.006 & $-0.012 *$ & 0.000 & 0.001 & $0.012 *$ & 0.002 & 0.002 & -0.004 \\
\hline first income quartile & 0.007 & 0.001 & $-0.027 * *$ & $-0.048 * * *$ & -0.002 & $-0.031 * * *$ & $-0.020 *$ & -0.012 & $0.052 * * *$ & $0.044 * * *$ & $-0.032 * * *$ \\
\hline second income quartile & -0.013 & -0.009 & 0.002 & $-0.027 * * *$ & $-0.021 *$ & $-0.041 * * *$ & $-0.022 * *$ & -0.010 & $0.020 *$ & $0.050^{* * *}$ & $-0.021 * *$ \\
\hline third income quartile & -0.007 & -0.004 & -0.005 & -0.011 & -0.001 & -0.014 & $-0.019 *$ & $-0.023 * *$ & 0.005 & $0.043 * * *$ & -0.006 \\
\hline undeclared income & 0.013 & 0.015 & 0.008 & -0.009 & 0.016 & -0.012 & -0.006 & -0.003 & 0.009 & 0.009 & $-0.020 * * *$ \\
\hline area of living: large town & $-0.024 * * *$ & $0.017^{* *}$ & -0.009 & -0.008 & -0.001 & $-0.030 * * *$ & 0.004 & 0.008 & $0.017 * *$ & $0.039 * * *$ & $-0.013 * *$ \\
\hline area of living: small town & 0.007 & $-0.017 * *$ & $0.020 * * *$ & -0.007 & -0.012 & $-0.043 * * *$ & 0.012 & -0.009 & $0.023 * * *$ & $0.025 * * *$ & $-0.016 * * *$ \\
\hline area of living: $\mathrm{dk}$ & 0.019 & $-0.104 * * *$ & -0.006 & -0.013 & 0.046 & $-0.088 * *$ & 0.044 & 0.002 & 0.019 & $0.154 * * *$ & $-0.103 * * *$ \\
\hline proud own nationality: high & $-0.048 * *$ & 0.001 & -0.013 & 0.027 & -0.015 & $0.038 * *$ & 0.002 & $-0.055 * * *$ & 0.023 & $-0.039 *$ & -0.007 \\
\hline proud own nationality: medium-high & -0.009 & -0.011 & 0.000 & 0.005 & -0.001 & $0.037 * *$ & -0.016 & $-0.044 * *$ & 0.027 & -0.026 & -0.004 \\
\hline proud own nationality: medium-low & -0.015 & $-0.034 *$ & -0.012 & -0.008 & -0.023 & $0.041 * *$ & 0.007 & -0.031 & $0.041 * *$ & -0.018 & -0.014 \\
\hline proud own nationality: $\mathrm{dk}$ & 0.039 & -0.033 & -0.015 & $-0.045 *$ & -0.025 & $0.072 * * *$ & $-0.071 * * *$ & $-0.052 * *$ & $0.061 * *$ & -0.001 & -0.006 \\
\hline proud European: high & -0.008 & $0.047 * * *$ & 0.010 & -0.015 & $-0.032 *$ & 0.015 & -0.014 & -0.013 & -0.022 & $0.048 * * *$ & 0.009 \\
\hline proud European: medium-high & -0.008 & $0.050 * * *$ & 0.006 & 0.001 & -0.019 & 0.016 & 0.000 & -0.015 & $-0.056 * * *$ & $0.037 * * *$ & $0.028 * * *$ \\
\hline proud European: medium-low & 0.003 & $0.053 * * *$ & $0.029 * *$ & 0.009 & -0.003 & $0.025 * *$ & -0.015 & 0.006 & $-0.054 * * *$ & $0.025 *$ & $0.046 * * *$ \\
\hline proud European: dk & -0.014 & $0.055 * * *$ & 0.022 & $0.024 *$ & -0.006 & -0.008 & -0.012 & 0.020 & $-0.070 * * *$ & $0.026 *$ & $0.037^{* * *}$ \\
\hline Europeanism & $0.038 * * *$ & $0.034^{* * *}$ & $0.038 * * *$ & $0.041^{* * *}$ & $0.039^{* * *}$ & $0.039 * * *$ & $0.044 * * *$ & $0.039 * * *$ & $0.040 * * *$ & $0.040 * * *$ & $0.028 * * *$ \\
\hline Constant & -0.022 & $0.130 * * *$ & $-0.192 * * *$ & 0.024 & $-0.187 * * *$ & 0.049 & -0.021 & 0.055 & -0.045 & -0.019 & $0.231 * * *$ \\
\hline Number of obs & 15939 & 15939 & 15939 & 15939 & 15939 & 15939 & 15939 & 15939 & 15939 & 15939 & 15939 \\
\hline Prob $>$ F & 0.000 & 0.000 & 0.000 & 0.000 & 0.000 & 0.000 & 0.000 & 0.000 & 0.000 & 0.000 & 0.000 \\
\hline R-squared & 0.387 & 0.366 & 0.394 & 0.425 & 0.373 & 0.402 & 0.443 & 0.372 & 0.382 & 0.408 & 0.373 \\
\hline
\end{tabular}


For example Sweden, which from the previous analysis resulted as one of the less pro-Europeanist countries, is found to be the country most in favour of centralisation when considering poverty and social exclusion and fight against international terrorism, and quite in support of EU competence with regard to environment, agriculture and regional aid.

In general, the "Europeanism ranking" varies with the area considered. For defence Dutch citizens are the most in favour of centralisation (followed by Italian citizens), while the more proEuropeanist countries when considering foreign policy are Belgium, Germany and Finland. Environment sees at the first place Germany, followed by UK, which according to the previous analysis resulted as one of the least pro-Europeanist country, and the Netherlands. Also when considering agriculture we observe a change in countries' ranking: Denmark is the most procentralisation country among the 15 considered (also with respect to regional aid), followed by Belgium, Germany, Sweden and the UK.

The ranking previously detected is substantially confirmed with regard to unemployment and education (which see Italy at the first place of pro-Europeanism). Interestingly, the more in favour of centralisation when immigration policy is considered are Mediterranean countries (i.e. Italy, Greece and Spain). Indeed, these countries are the nearest to North-Africa and Middle East and thus more than other EU countries they have to cope with migration flows from this area (also when they are directed to other European countries). Thus, similar geographical conditions with respect to the scope for protecting national borders determine a common attitude for coordination and centralisation among these countries when considering immigration.

Turning to the impact of other regressors, female citizens are more in favour of centralisation than men with regard to research, unemployment, education and immigration, and less with regard to regional aid. Oldest Europeans prefer a national competence when considering foreign policy, poverty and social exclusion and regional aid (the opposite is true for agriculture). In general labour market status and profession is not related to preferences for centralisation, with some noteworthy exceptions. For example (and surprisingly given the high budget share spent on agriculture by EU) farmer and fisherman are more in favour of a national competence for agriculture. This result might be linked to rules for price and quantity often imposed by EU.

The higher preference for centralisation of left affiliated citizens is not confirmed for education, as in this case right affiliated Europeans are more likely to prefer centralisation. However, right affiliated citizens confirm their preference for national competence with regard to poverty and social exclusion, agriculture and immigration.

As expected, when the attitude towards own country's membership is good or neutral (with respect to bed), for almost all domains (with only exception of education) we observe a higher probability of preference for centralised competence, while there is hardly no impact of the variable indicating 
whether the citizen considers his/her own country has on balance benefited from membership. Similarly, the impact of how citizens feel themselves European, the level of own country and EU democracy satisfaction and the degree of citizens' pride to be European and of own nationality depends on the considered domain and in general we detect no clear pattern.

Happier citizens are more Europeanist when considering environment and immigration and less when considering unemployment and education. More informed citizens are pro-centralisation for environment, agriculture and fight against international terrorism; interestingly, preference for allocation to competence to EU are in some cases influenced by frequency by which citizens learn news, but the impact changes with the information source considered.

Finally, poorest citizens are more likely to prefer national competence with reference to poverty and social exclusion, research, unemployment and fight against terrorism, while they are more proEuropeanist when considering education and immigration.

\section{Conclusions and policy implications}

It is well known that one of the critical issues debated inside the European Convention was to clarify the allocation of powers and prerogatives among the European level and member states. However the French and Dutch "no" to the Constitution has opened a period of reflection which implies a critical review of European Union's success and failure but at the same time a view to relaunch European construction and to prepare a new Europe's future. In this contest, we believe that it crucial and very important to gain a better understanding of how European citizens perceive the image and the action of the European Union.

In this paper we intended to proceed in this direction by studying to what extent preferences of European citizens concerning the allocation of powers between EU and the member States follow the clear-cut allocation suggested by the theory of fiscal federalism.

Descriptive analysis highlighted interesting results pointing out a ranking of countries according to their level of Europeanism, and a quite clear pattern of preferences relative to competence allocation for specific policy domains. In other words, we have identified that there are some policy fields in which clear majorities exist for either centralization (for instance terrorism) or decentralization (for instance education). On the other hand there are some policy domains (such as defence, immigration, policies for tackling the challenge of an ageing population, rules for political asylum, unemployment and agriculture) where heterogeneity across countries can be observed. These results may suggest directions for a more flexible integration strategy in the allocation of these powers. In order to avoid the danger of a misallocation of political competencies, a policy area should be allocated at the EU level when a coalition of countries - with strong common preferences - will prevail. 
Next, with econometric analysis, our aim has been to elaborate a set of possible determinants of the observed distribution of preferences. So we studied more deeply the issue of preference for competence allocation, first regressing a measure of "Europeanism" of EU citizens on a number of individual characteristics, including demographic information and various indicators of the attitude towards EU, and secondly, selecting a certain number of policy domains and, for each of these, investigating which individual characteristics make European citizens more prone to prefer centralisation of competences. Also econometric analysis revealed interesting patterns regarding EU citizens' preferences for the allocation of powers. In particular, there are clear-cut country patterns in the level of Europeanism and a ranking among countries emerges: the less pro-European countries are those in Scandinavia (Finland and Sweden), Denmark and Luxemburg; countries from Anglo-Saxon Europe (Ireland and UK), The Netherlands and Austria follow next. The third group is made up of France and Germany, which exhibit a higher degree of Europeanism, while the more pro-European countries are those from Southern Europe (Portugal, Spain, Greece and Italy) and Belgium. However, when we turned to determinants of preference regarding allocation of competence for specific policy issues, other important insights emerged. For example, Sweden, which resulted as one of the less pro-Europeanist countries, is found to be the country most in favour of centralisation when considering poverty and social exclusion and fight against international terrorism, and quite in support of EU competence when environment, agriculture and regional aid. To conclude, the "Europeanism ranking" varies with the area considered. 


\section{References}

Ahmad, E. and Brosio, G. (eds) (2006), Handbook of Fiscal Federalism, Cheltenham and Northampton: Edward Elgar.

Ahrens, J., Meurers, M. and Renner, C. (2004), Beyond the Big-Bang Enlargement of the EU: Preferences and the Need for Flexibility, mimeo.

Alesina, A., Angeloni, I. and Etro, F. (2005), "International Unions" American Economic Review, 95, pp. 602-615.

Alesina, A., Angeloni, I. and Schuknecht, L. (2005), "What does the European Union do?" Public Choice, 123, pp. 275-319.

Alesina, A. and Perotti, R. (2004), “The European Union: A Politically Incorrect View?”, Journal of Economic Perspective, 18, pp. 22-48.

Alesina, A. and Spolaore, E. (2003), The size of nations, Cambridge, Ma and London: MIT press.

Anderson, C. J., and Kalthenthaler, K. C. (1996) The Dynamics of Public Opinion toward European Integration 1973-93, European Journal of International Relations, Vol. 2, N. 2, pp. 175-1999.

Berger, H. and Moutos, T. (eds) (2007), Designing the New European Union, Amsterdam: Elsevier.

Bordignon, M. (2006), "Institutional Aspects of EU organization: An Economic Analysis", in Berger, H. and Moutos, T. (eds) (2007), Designing the New European Union, Amsterdam: Elsevier.

Breuss, F. and Eller, M. (2003) "On the optimal assignment of Competences in a Multi-Level Governed EU", European Integration online Papers, Vol. 7, N. 8, available at http://eiop.or.at

Dafflon, B. (2006) "The assignment of functions to decentralized government: from theory to practice", in Ahmad, E. and Brosio, G. (eds) (2006), Handbook of Fiscal Federalism, Cheltenham and Northampton: Edward Elgar.

Kaufmann, D., Kraay, A. and Mastruzzi, M. (2005), Governance Indicators for 1996-2004. Website: http://info.worldbank.org/governance/kkz2005/.

Inman, R. and Rubinfeld, D. (1998) "Subsidiarity and the European Union”, NBER Working Paper, No. 6556.

Lockwood, B. (2006) "The political economy of decentralization”, in Ahmad, E. and Brosio, G. (eds) (2006), Handbook of Fiscal Federalism, Cheltenham and Northampton: Edward Elgar

Louviere, J. J., Hensher. D. A. and Swatt, J. D. (2000), Stated choice methods - Analysis and Application, Cambridge: Cambridge University Press.

Oates, W. (1972), Fiscal Federalism, New York: Harcourt-Brace.

Oates, W. (1999), “An essay on fiscal federalism”, Journal of Economic Literature, 37, pp.1120-49.

Tabellini, G. (2003), "Principles of Policymaking in the European Union: An Economic Perspective" CESifo Economic Studies, 49, pp. 75-102.

Wellish, D. (2000), Theory of public finance in a federal State, Cambridge: Cambridge University Press.

Wilson, J. (2006), "Tax competition in a federal setting”, in Ahmad, E. and Brosio, G. (eds) (2006), Handbook of Fiscal Federalism, Cheltenham and Northampton: Edward Elgar. 


\section{CESifo Working Paper Series}

for full list see www.cesifo-group.org/wp

(address: Poschingerstr. 5, 81679 Munich, Germany, office@cesifo.de)

2004 Harrie A. A. Verbon, Migrating Football Players, Transfer Fees and Migration Controls, May 2007

2005 Helmuth Cremer, Jean-Marie Lozachmeur and Pierre Pestieau, Income Taxation of Couples and the Tax Unit Choice, May 2007

2006 Michele Moretto and Paolo M. Panteghini, Preemption, Start-Up Decisions and the Firms’ Capital Structure, May 2007

2007 Andreas Schäfer and Thomas M. Steger, Macroeconomic Consequences of Distributional Conflicts, May 2007

2008 Mikael Priks, Judiciaries in Corrupt Societies, June 2007

2009 Steinar Holden and Fredrik Wulfsberg, Downward Nominal Wage Rigidity in the OECD, June 2007

2010 Emmanuel Dhyne, Catherine Fuss, Hashem Pesaran and Patrick Sevestre, Lumpy Price Adjustments: A Microeconometric Analysis, June 2007

2011 Paul Belleflamme and Eric Toulemonde, Negative Intra-Group Externalities in TwoSided Markets, June 2007

2012 Carlos Alós-Ferrer, Georg Kirchsteiger and Markus Walzl, On the Evolution of Market Institutions: The Platform Design Paradox, June 2007

2013 Axel Dreher and Martin Gassebner, Greasing the Wheels of Entrepreneurship? The Impact of Regulations and Corruption on Firm Entry, June 2007

2014 Dominique Demougin and Claude Fluet, Rules of Proof, Courts, and Incentives, June 2007

2015 Stefan Lachenmaier and Horst Rottmann, Effects of Innovation on Employment: A Dynamic Panel Analysis, June 2007

2016 Torsten Persson and Guido Tabellini, The Growth Effect of Democracy: Is it Heterogenous and how can it be Estimated?, June 2007

2017 Lorenz Blume, Jens Müller, Stefan Voigt and Carsten Wolf, The Economic Effects of Constitutions: Replicating - and Extending - Persson and Tabellini, June 2007

2018 Hartmut Egger and Gabriel Felbermayr, Endogenous Skill Formation and the Source Country Effects of International Labor Market Integration, June 2007

2019 Bruno Frey, Overprotected Politicians, June 2007 
2020 Jan Thomas Martini, Rainer Niemann and Dirk Simons, Transfer Pricing or Formula Apportionment? Tax-Induced Distortions of Multinationals' Investment and Production Decisions, June 2007

2021 Andreas Bühn, Alexander Karmann and Friedrich Schneider, Size and Development of the Shadow Economy and of Do-it-yourself Activities in Germany, June 2007

2022 Michael Rauscher and Edward B. Barbier, Biodiversity and Geography, June 2007

2023 Gunther Schnabl, Exchange Rate Volatility and Growth in Emerging Europe and East Asia, June 2007

2024 Erkki Koskela and Ronnie Schöb, Tax Progression under Collective Wage Bargaining and Individual Effort Determination, June 2007

2025 Jay Pil Choi and Marcel Thum, The Economics of Politically Connected Firms, June 2007

2026 Jukka Pirttilä and Roope Uusitalo, Leaky Bucket in the Real World: Estimating Inequality Aversion Using Survey Data, June 2007

2027 Ruslan Lukach, Peter M. Kort and Joseph Plasmans, Strategic R\&D with Knowledge Spillovers and Endogenous Time to Complete, June 2007

2028 Jarko Fidrmuc, Neil Foster and Johann Scharler, Labour Market Rigidities, Financial Integration and International Risk Sharing in the OECD, June 2007

2029 Bernardina Algieri and Thierry Bracke, Patterns of Current Account Adjustment Insights from Past Experience, June 2007

2030 Robert Dur and Hein Roelfsema, Social Exchange and Common Agency in Organizations, June 2007

2031 Alexander Libman and Lars P. Feld, Strategic Tax Collection and Fiscal Decentralisation: The Case of Russia, June 2007

2032 Øystein Foros, Hans Jarle Kind and Greg Shaffer, Resale Price Maintenance and Restrictions on Dominant Firm and Industry-Wide Adoption, June 2007

2033 Jan K. Brueckner and Kurt Van Dender, Atomistic Congestion Tolls at Concentrated Airports? Seeking a Unified View in the Internalization Debate, June 2007

2034 Viet Do and Ngo Van Long, International Outsourcing under Monopolistic Competition: Winners and Losers, June 2007

2035 Nadia Fiorino and Roberto Ricciuti, Determinants of Direct Democracy, June 2007

2036 Burkhard Heer and Alfred Maussner, Inflation and Output Dynamics in a Model with Labor Market Search and Capital Accumulation, June 2007 
2037 Konstantinos Angelopoulos, Jim Malley and Apostolis Philippopoulos, Public Education Expenditure, Growth and Welfare, June 2007

2038 Maarten Bosker, Steven Brakman, Harry Garretsen and Marc Schramm, Adding Geography to the New Economic Geography, June 2007

2039 Steffen Henzel, Oliver Hülsewig, Eric Mayer and Timo Wollmershäuser, The Price Puzzle Revisited: Can the Cost Channel Explain a Rise in Inflation after a Monetary Policy Shock?, July 2007

2040 Rosario Crinò, Service Offshoring and White-Collar Employment, July 2007

2041 Carsten Hefeker and Michael Neugart, Labor Market Regulation and the Legal System, July 2007

2042 Bart Cockx and Muriel Dejemeppe, Is the Notification of Monitoring a Threat to the Unemployed? A Regression Discontinuity Approach, July 2007

2043 Alfons J. Weichenrieder, Profit Shifting in the EU: Evidence from Germany, July 2007

2044 Annika Alexius and Bertil Holmlund, Monetary Policy and Swedish Unemployment Fluctuations, July 2007

2045 Axel Dreher, Jan-Egbert Sturm and Jakob de Haan, Does High Inflation Cause Central Bankers to Lose their Job? Evidence Based on a New Data Set, July 2007

2046 Guglielmo Maria Caporale and Luis A. Gil-Alana, Long Run and Cyclical Dynamics in the US Stock Market, July 2007

2047 Alessandro Balestrino, It is a Theft but not a Crime, July 2007

2048 Daniel Becker and Michael Rauscher, Fiscal Competition in Space and Time: An Endogenous-Growth Approach, July 2007

2049 Yannis M. Ioannides, Henry G. Overman, Esteban Rossi-Hansberg and Kurt Schmidheiny, The Effect of Information and Communication Technologies on Urban Structure, July 2007

2050 Hans-Werner Sinn, Please bring me the New York Times - On the European Roots of Richard Abel Musgrave, July 2007

2051 Gunther Schnabl and Christian Danne, A Role Model for China? Exchange Rate Flexibility and Monetary Policy in Japan, July 2007

2052 Joseph Plasmans, Jorge Fornero and Tomasz Michalak, A Microfounded Sectoral Model for Open Economies, July 2007

2053 Vesa Kanniainen and Panu Poutvaara, Imperfect Transmission of Tacit Knowledge and other Barriers to Entrepreneurship, July 2007 
2054 Marko Koethenbuerger, Federal Tax-Transfer Policy and Intergovernmental PreCommitment, July 2007

2055 Hendrik Jürges and Kerstin Schneider, What Can Go Wrong Will Go Wrong: Birthday Effects and Early Tracking in the German School System, July 2007

2056 Bahram Pesaran and M. Hashem Pesaran, Modelling Volatilities and Conditional Correlations in Futures Markets with a Multivariate t Distribution, July 2007

2057 Walter H. Fisher and Christian Keuschnigg, Pension Reform and Labor Market Incentives, July 2007

2058 Martin Altemeyer-Bartscher, Dirk T. G. Rübbelke and Eytan Sheshinski, Policies to Internalize Reciprocal International Spillovers, July 2007

2059 Kurt R. Brekke, Astrid L. Grasdal and Tor Helge Holmås, Regulation and Pricing of Pharmaceuticals: Reference Pricing or Price Cap Regulation?, July 2007

2060 Tigran Poghosyan and Jakob de Haan, Interest Rate Linkages in EMU Countries: A Rolling Threshold Vector Error-Correction Approach, July 2007

2061 Robert Dur and Klaas Staal, Local Public Good Provision, Municipal Consolidation, and National Transfers, July 2007

2062 Helge Berger and Anika Holler, What Determines Fiscal Policy? Evidence from German States, July 2007

2063 Ernesto Reuben and Arno Riedl, Public Goods Provision and Sanctioning in Privileged Groups, July 2007

2064 Jan Hanousek, Dana Hajkova and Randall K. Filer, A Rise by Any Other Name? Sensitivity of Growth Regressions to Data Source, July 2007

2065 Yin-Wong Cheung and Xing Wang Qian, Hoarding of International Reserves: Mrs Machlup’s Wardrobe and the Joneses, July 2007

2066 Sheilagh Ogilvie, 'Whatever Is, Is Right'?, Economic Institutions in Pre-Industrial Europe (Tawney Lecture 2006), August 2007

2067 Floriana Cerniglia and Laura Pagani, The European Union and the Member States: Which Level of Government Should Do what? An Empirical Analysis of Europeans' Preferences, August 2007 